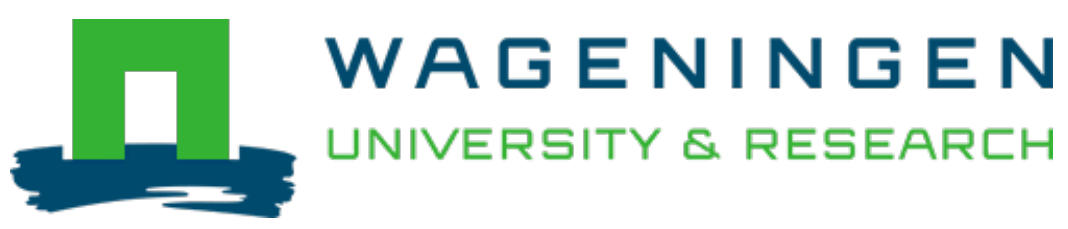

\title{
Ecosystem coupling: A unifying framework to understand the functioning and recovery of ecosystems
}

\author{
One Earth \\ Ochoa-Hueso, R.; Delgado-Baquerizo, Manuel; Risch, A.C.; Schrama, Maarten; Morriën, Elly et al \\ https://doi.org/10.1016/j.oneear.2021.06.011
}

This article is made publicly available in the institutional repository of Wageningen University and Research, under the terms of article $25 \mathrm{fa}$ of the Dutch Copyright Act, also known as the Amendment Taverne. This has been done with explicit consent by the author.

Article 25 fa states that the author of a short scientific work funded either wholly or partially by Dutch public funds is entitled to make that work publicly available for no consideration following a reasonable period of time after the work was first published, provided that clear reference is made to the source of the first publication of the work.

This publication is distributed under The Association of Universities in the Netherlands (VSNU) 'Article $25 \mathrm{fa}$ implementation' project. In this project research outputs of researchers employed by Dutch Universities that comply with the legal requirements of Article $25 \mathrm{fa}$ of the Dutch Copyright Act are distributed online and free of cost or other barriers in institutional repositories. Research outputs are distributed six months after their first online publication in the original published version and with proper attribution to the source of the original publication.

You are permitted to download and use the publication for personal purposes. All rights remain with the author(s) and / or copyright owner(s) of this work. Any use of the publication or parts of it other than authorised under article $25 \mathrm{fa}$ of the Dutch Copyright act is prohibited. Wageningen University \& Research and the author(s) of this publication shall not be held responsible or liable for any damages resulting from your (re)use of this publication.

For questions regarding the public availability of this article please contact openscience.library@wur.nl 


\section{Ecosystem coupling: A unifying framework to understand the functioning and recovery of ecosystems}

Raúl Ochoa-Hueso, ${ }^{1,2, *}$ Manuel Delgado-Baquerizo, ${ }^{3}$ Anita C. Risch, ${ }^{4}$ Maarten Schrama, ${ }^{5}$ Elly Morriën, ${ }^{6}$ S. Henrik Barmentlo, ${ }^{5,6}$ Stefan Geisen, ${ }^{7}$ S. Emilia Hannula, ${ }^{2}$ M. Carol Resch, ${ }^{4}$ Basten L. Snoek, ${ }^{8}$ and Wim H. van der Putten 2,7

1Department of Biology, IVAGRO, University of Cádiz, Campus de Excelencia Internacional Agroalimentario (CeiA3), Campus del Rio San Pedro, 11510 Puerto Real, Cádiz, Spain

2Department of Terrestrial Ecology, Netherlands Institute of Ecology (NIOO-KNAW), P.O. Box 50, 6700 AB Wageningen, the Netherlands ${ }^{3}$ Departamento de Sistemas Físicos, Químicos y Naturales, Universidad Pablo de Olavide, 41013 Sevilla, Spain

${ }^{4}$ Swiss Federal Institute for Forest, Snow and Landscape Research WSL, Community Ecology, Zuercherstrasse 111, 8903 Birmensdorf, Switzerland

${ }^{5}$ Department of Environmental Biology, Institute of Environmental Sciences, Leiden University, Leiden, the Netherlands

${ }^{6}$ Department of Ecosystem and Landscape Dynamics, Institute of Biodiversity and Ecosystem Dynamics (IBED-ELD), University of

Amsterdam, P.O. Box 94240, 1090 GE Amsterdam, the Netherlands

${ }^{7}$ Laboratory of Nematology, Wageningen University and Research, 6708PB Wageningen, the Netherlands

8Theoretical Biology and Bioinformatics, Utrecht University, $3584 \mathrm{CH}$ Utrecht, the Netherlands

*Correspondence: rochoahueso@gmail.com

https://doi.org/10.1016/j.oneear.2021.06.011

\section{SUMMARY}

Global change frequently disrupts the connections among species, as well as among species and their environment, before the most obvious impacts can be detected. Therefore, we need to develop a unified conceptual framework that allows us to predict early ecological impacts under changing environments. The concept of coupling, defined as the multiple ways in which the biotic and abiotic components of ecosystems are orderly connected across space and/or time, may provide such a framework. Here, we operationally define the coupling of ecosystems based on a combination of correlational matrices and a null modeling approach. Compared with null models, ecosystems can be (1) coupled; (2) decoupled; and (3) anticoupled. Given that more tightly coupled ecosystems displaying higher levels of internal order may be characterized by a more efficient capture, transfer, and storage of energy and matter (i.e., of functioning), understanding the links between coupling and functioning may help us to accelerate the transition to planetary-scale sustainability. This may be achieved by promoting self-organized order.

\section{INTRODUCTION}

Ecosystems are currently being simultaneously affected by multiple anthropogenic global changes such as land-use intensification, climate change, biological invasions, excessive use of biocides and fertilizers, $\mathrm{N}$ deposition, and elevated atmospheric $\mathrm{CO}_{2}{ }^{1,2}$ These global changes affect plant, faunal, and microbial biodiversity and communities across all trophic levels, ${ }^{2}$ which may severely compromise the ability of ecosystems to maintain multiple functions and services, and to withstand future global change. ${ }^{3}$ These perturbations can also disrupt the connections among species, as well as between species and their environment, with far-reaching consequences for the future trajectory and functioning of entire ecosystems. ${ }^{4,5}$ Actually, it is now widely accepted that the disappearance of particular taxa is frequently preceded by the loss of ecological connections on which these taxa depend. ${ }^{4}$ However, classic statistical methods that, for example, compare means and standard deviations using $p$ values may not have enough resolution to detect these changes, particularly in the short term. Hence, it is essential to develop tools derived from unified conceptual frameworks that allow us to predict the early changes in communities and ecosystem properties and functions under changing environments. ${ }^{6}$ The concept of coupling, recurrently used by many disciplines and inextricably linked to the energetics of interconnected systems, ${ }^{7-10}$ may provide such a framework.

Here, we start paving the way toward the development of a unified framework for the concept of coupling in ecology. We also discuss the importance of losing coupled connections among species/communities, among species/communities and their abiotic environment, and among biogeochemical cycles across contrasting terrestrial and aquatic ecosystems under global change. In addition, we also discuss the consequences of these losses in terms of ecosystem functioning, widely regarded as a measure of the rate of energy/matter exchange within a given system, ${ }^{11}$ and thus for the provisioning of services. Finally, 


\section{CellPress}

we explore how we may be able to use information on changes in biotic, biotic-abiotic, and biogeochemical couplings to guide the regeneration of sustainable ecosystems, ${ }^{12}$ as well as the future of ecological intensification of agroecosystems. ${ }^{13-15}$ In doing so, we provide a roadmap toward a more unified manner of understanding how the multiple and highly dynamic coupled connections that are established among the biotic and abiotic compartments of ecosystems define how these ecosystem function (i.e., how they exchange information, energy, and matter), how they respond to global environmental changes, and how they can be engineered toward sustainability.

\section{DEFINING ECOSYSTEM COUPLING ACROSS SCALES}

The term coupling has a long history in science, being commonly used by many disciplines such as physics, chemistry, engineering, biology, and Earth sciences to refer to a range of concepts that always seem to have in common the interdependency of two or more parts of a whole system for its functioning. ${ }^{7-10}$ As such, the concept of coupling is always inextricably linked to the exchange of energy and/or matter. ${ }^{16,17}$ For example, it is well established that the metabolism of all living organisms depends on the precise coupling of a myriad of chemical reactions involving millions of molecules. ${ }^{10,18}$ In Earth sciences, the term coupling has been used most frequently to refer to the interdependency among the different elemental cycles (for example, $\mathrm{C}, \mathrm{N}$, and P) that define the biogeochemistry of our planet, ${ }^{9}$ and also to how the atmosphere-ocean-land subsystems are linked to one another through the exchange of energy and matter. ${ }^{19}$ Actually, the coupling of ecological systems has been an implicit assumption of ecosystem scientists since the times of Vernadsky, Lindeman, and Odum, ${ }^{20,21}$ and even Humboldt and Darwin. ${ }^{22-24}$ However, to date there is still a lack of a common definition and unified conceptual framework for this term. For example, in terrestrial ecology, the term coupling has often been assimilated with changes in the elemental stoichiometry of plants ${ }^{25,26}$ and soils, ${ }^{27,28}$ while in aquatic ecology the term coupling usually refers to changes in food-web dynamics involving the benthic-pelagic systems. ${ }^{29,30}$ More recently, Risch et al. ${ }^{31}$ used the term coupling to refer to the degree of spatial cooccurrence among communities, and of communities with their abiotic environment, both aboveground and belowground, within alpine grasslands. However, the concept of coupling in ecology has not been formally defined and tested in a systemlevel integrative way, preventing its wider applicability.

Here, we define the term coupling as the multiple ways in which the biotic and abiotic components of ecosystems are orderly connected across space and/or time. This definition also implies a tight link between such ordered connections and the energetics of complex systems. Day-to-day examples of these couplings include the associations typically found between vascular plants and mycorrhizal symbionts, ${ }^{32}$ plants, and soil $\mathrm{pH}$ and texture, ${ }^{33,34}$ and the interdependencies among the $\mathrm{C}, \mathrm{N}$, and $\mathrm{P}$ cycles, which are determined by the chemical reactivity of molecules containing those elements and by the metabolism of living organisms. ${ }^{35}$ Of course, we acknowledge that, as defined here, the level of coupling will be highly dependent on the scale at which it is investigated, and thus the importance of the spatial and/or temporal scale considered may also vary according to intrinsic characteristics of the coupled components (e.g., lifespan and size in the case of biotic components). Thus, it seems reasonable to suggest that, to properly define how systems are coupled, we may need to refer simultaneously to several scales, as represented in spatial and temporal correlograms. Identifying which spatial and temporal scales are more relevant to define how systems are coupled must thus precede the study of coupling itself, and sometimes a compromise scale of study may need to be selected when the couplings between components that vary greatly in size/time span are evaluated (e.g., plant-microbe interactions across a field site; Box 1).

Despite some inherent similarities, we believe that our proposed concept of coupling goes beyond, and differs from, ecological network or food-web theory, because it takes the focus away from trophic and non-trophic interactions, and/or biogeochemical processes. Instead, it moves the focus toward the role of spatial and temporal self-organization of ecosystems. ${ }^{43}$ Thus, our definition of coupling is also highly linked to the concept of homeostasis, which refers to the ability of systems to self-regulate and stay away from a more disordered state of lower energy status, ${ }^{44}$ with a self-reorganization and self-regulation that can operate at different scales, or even simultaneously across scales. Actually, if coupling is maintained invariably unchanged across scales (i.e., coupling is scale invariant), this will lead to what we define as fractal coupling, a concept that may actually be critical to understanding how the brain works ${ }^{45}$ and that may also share commonalities with the model of allometric scaling. ${ }^{46}$

Importantly, this self-reorganization is driven by three main forces (Figure 1A): (1) the inevitable underlying laws of both large-object and small-particle physics (e.g., atomic properties of chemical elements, gravity, quantum mechanics), which set the limits of how the components of ecosystems, and their constituent elements, may interact with one another at different spatial scales (i.e., from the infinitesimally small to the nano, micro, and macro scales $)^{47}$; (2) the metabolism, nutritional demands, stoichiometric constraints, and behavior of individual organisms, ${ }^{43}$ all of them associated with the niche breadth of the species to which these organisms belong ${ }^{48}$; and (3) the underlying mechanisms that define how communities are structured, including competition, facilitation, and symbiosis, ${ }^{49}$ which are directly related to the realized niche of those interacting species. $^{50}$

By moving the emphasis away from inter- and intra-specific interactions, or from simple environmental correlational associations, toward the key role of spatial and temporal self-organization and self-sustainability of ecosystems at different scales and the physical, chemical, and biological factors driving them, our newly proposed concept of coupling in ecology provides a novel integrative framework for understanding and making sense of the multiple positive and negative associations typically found within and between organisms and environmental properties, and their implications for the functioning of ecosystems. ${ }^{51,52}$ In other words, within the framework of coupling, we are interested in understanding how systems are ordered, how that order is achieved and/or maintained away from a hypothetically more disordered state, and what that means in terms of ecosystem functioning. This must always be a reflection of how energy/matter are stored and/or move through and in and out of the 


\section{Box 1. Beyond terrestrial plants: Applying the concept of coupling to soils and plant-soil systems}

Most of the current evidence of spatially and temporally coupled ecosystems is based on terrestrial plant communities, while we know much less about changes in the spatial and temporal couplings of the soil subsystem. This can be attributed to obvious reasons, such as the fact that plants cannot move and are thus easier to work with, and that the spatial scale at which we can work with them is amenable to simple human observation. However, it is well known that soil microorganisms are tightly coupled to their physicochemical environment through a continuous flow of electrons, making this a particularly promising field of research. For example, the abundance and community composition of soil invertebrates and microbes are widely known to be driven by (i.e., coupled to) climatic conditions, soil properties such as soil $\mathrm{pH}$ and organic matter content, and vegetation type. ${ }^{36}$ As a result of these couplings, invertebrate and microbial communities, including bacteria, archaea, fungi, and protists, drive the functioning of soils worldwide through their direct and indirect control on nutrient cycling, ecosystem $\mathrm{C}$ storage, and greenhouse gas fluxes. ${ }^{37,38}$ However, we still lack a clear understanding of the mechanisms through which changes in biotic and biotic-abiotic couplings may mediate the response of spatially and temporally coupled soil communities to global environmental change. However, given that changes in the structure and activity of soil communities may determine changes in ecosystem functioning, ${ }^{39,40}$ detecting the subtle effects of perturbations on such soil systems can be of great, but perhaps underappreciated, importance. Unraveling this will require the synchronous collection of spatially explicit ecological data at a spatial and temporal scale that are simultaneously relevant for microbes, soil invertebrates, plants, and also the many ecosystem-scale processes that depend on them. ${ }^{39}$ Continuous monitoring of permanent fine-scale, highly replicated, and spatially explicit sampling designs (e.g., grids) in the context of ongoing and future global change manipulation experiments and coordinated networks is likely to be one of the best options to approach this type of question. ${ }^{41,42}$

system. ${ }^{11}$ The mechanisms involved in the process of achieving/ maintaining that ordered state must necessarily comply with the rules of the second law of thermodynamics (i.e., the entropy principle) and be a combination of those previously mentioned three main forces.

\section{MEASURING COUPLING}

The next natural question would be how to measure such couplings. ${ }^{53}$ Operationally, one possible way to define coupling is based on the mean strength of pairwise associations/correlations in absolute value among biotic (i.e., including plant, animal, microbial species/communities), abiotic (e.g., precipitation/water, soil $\mathrm{pH}$, chemicals, texture), and elemental (i.e., C, N, P, K, etc.) properties/constituents of ecosystems ${ }^{31,54}$ (Figures 1 and 2). The consideration of correlations, which reflect order, in absolute value is critical to this concept given that the focus is on the ability of ecosystems and their properties to self-organize, regardless of the positive or negative sign of those correlations. Importantly, this approach may be applied to spatial data (i.e., correlations between two or more ecosystem attributes across space; hereafter, spatial coupling), as well as to temporal data (i.e., correlations between two or more ecosystem attributes across time; hereafter, temporal coupling).

One approach could involve the use of Spearman rank correlations, which are robust to lack of data normality and, most importantly, are based on order. When spatially explicit information is available, then the Tjøstheim's rank correlation coefficient ${ }^{56}$ may also be a suitable alternative. Moreover, the widespread consideration of non-linear associations (e.g., quadratic or even cubic relationships) may also prove critical for the future study of ecosystem coupling, as demonstrated by Ochoa-Hueso. ${ }^{55}$ The mean strength of coupling (i.e., as defined by the mean of all correlation coefficients in absolute value across the coupling matrix) should then be compared against a confidence interval derived from a randomly generated null model calculated using the same dataset (Figures 1B and 2A). A two-tailed statistical signifi- cance at the level of choice (e.g., $p<0.05, p<0.01$, etc.) can then be established based on permutations.

Ecosystem coupling indices of individual ecosystem properties/constituents can also be calculated by considering only those correlations involving that specific property/constituent. Considering a two-tailed significance is also a critical aspect of perhaps unappreciated importance because, within this definition, systems can be less coupled than what it is expected by chance (Figure 1B). Paradoxically, this may actually be interpreted as a kind of order, or perhaps, better defined, of anti-order. We then define the coupling states that fall above the confidence envelope as coupled, those that fall within the envelope as decoupled, and those that fall below that envelope as anticoupled. These decouplings and anticouplings are best exemplified by thinking of some flats shared by students, in which elements may normally be found in a disordered state (i.e., decoupled) and occasionally, for example after a wild party, more disorganized than what it is expected by pure chance (e.g., the possibilities of finding a shoe in the sink increase after the party). Alternative approaches that have already been used in the ecological literature to estimate ecosystem coupling are summarized in Table 1.

\section{THREE PROPOSED FORMS OF COUPLING IN ECOSYSTEMS}

\section{Biotic coupling}

The concept of coupling, as we have now defined it, is broad enough to accommodate any type of biotic, biotic-abiotic, or biogeochemical connections within ecosystems. ${ }^{63}$ When only biotic connections are considered, we define this as biotic coupling (Figures 1 and 2). Biotic connections, regardless of their sign (i.e., positive or negative), are crucial for ecosystem resistance, ${ }^{64}$ which is typically associated with the ability of ecosystems to withstand environmental stress without a change in ecosystem functioning. ${ }^{65}$ In practical terms, this type of coupling can be used to investigate the associations between organisms 
A

\section{Environmental degradation}

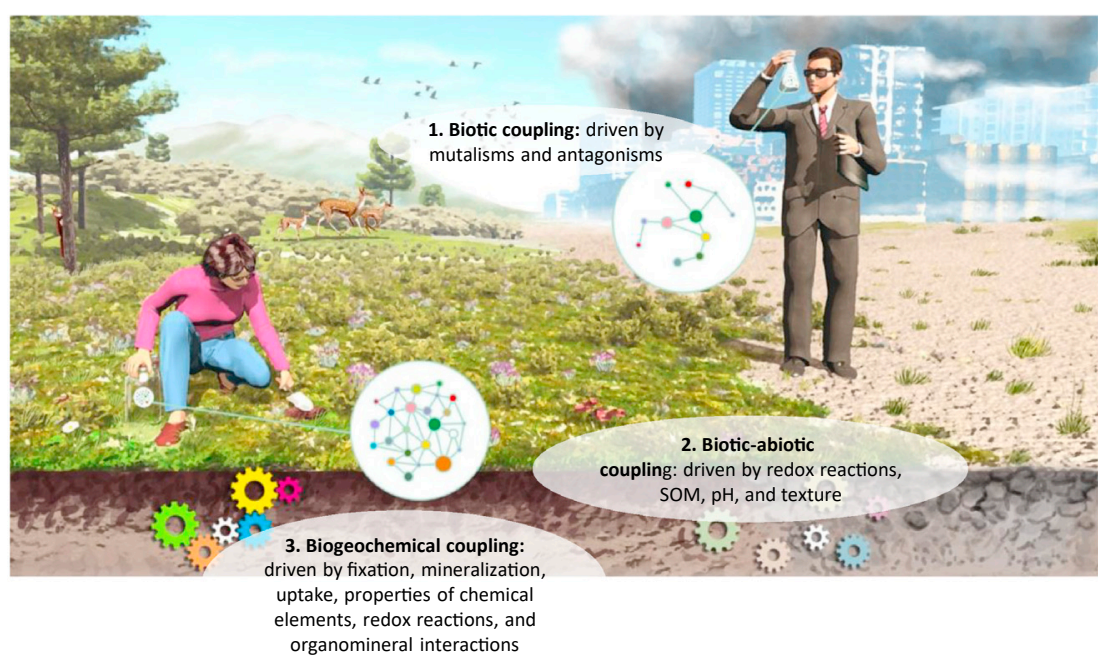

\section{Ecosystem coupling}

B
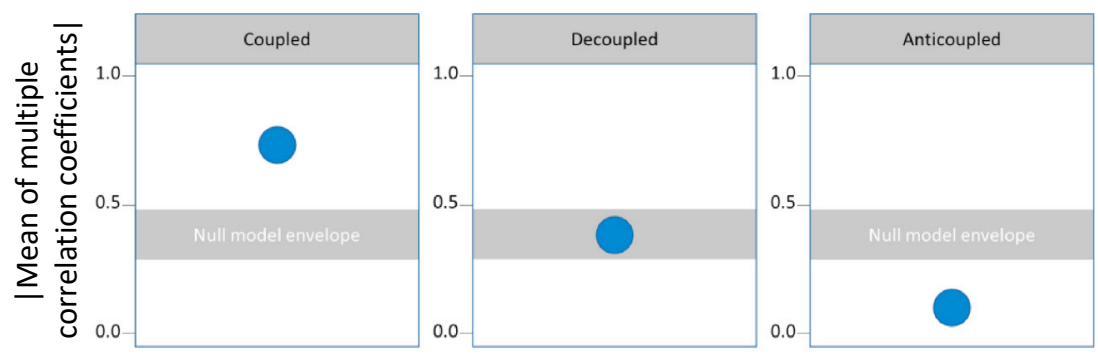

\section{C}

Greatest biodiversity and coupling

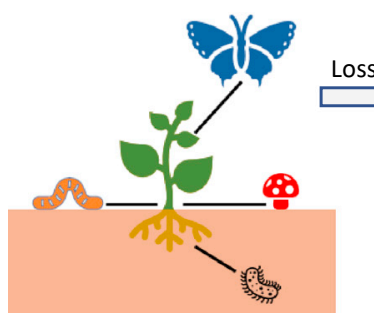

Disruptions of interactions without biodiversity loss with biodiversity loss
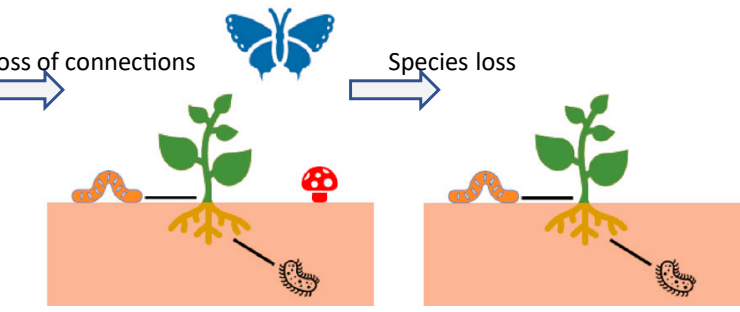

Disruptions of interactions

Figure 1. Mechanistic representation of the relationship between ecosystem coupling and biodiversity loss under global change scenarios

(A) Conceptual representation of biotic, bioticabiotic, and biogeochemical coupling.

(B) The three main proposed ways to be coupled based on a null modeling approach.

(C) On the left-hand side, different biotic ecosystem components are tightly coupled through the central role of the plant community. Environmental degradation (for example, due to climate change and nutrient enrichment) decouples the relationships between plants and the pollinator and mycorrhizal fungi due to a warming-driven phenological mismatch and excessive $\mathrm{N}$ and $\mathrm{P}$ in the soil, respectively. In this situation, biodiversity has not changed yet, and community-level effects may still not be detectable, but there is already a net loss of biotic ecosystem coupling. This may be shown by alterations in the spatial and temporal distribution patterns of those organisms. On the right-hand side, the pollinator and fungal species have already disappeared from the ecosystem because of the loss of coupling of their relationship with plants, resulting in a net biodiversity loss and a significant community change, with potentially relevant functional implications.

and antagonisms (e.g., competition, predation, herbivory, parasitism, pathogenicity) that often occur between microbes, plants, and animals. ${ }^{24,52}$

\section{Biotic-abiotic coupling}

The composition and functioning of all ecosystems on Earth are also highly constrained by the filtering forces imposed by the environmental conditions to which communities of interacting organisms are exposed. Thus, coupling can also be defined based on connections among biotic (e.g., soil communities) and abiotic (e.g., soil physical-chemistry, climatic conditions) properties of ecosystems. ${ }^{68,69}$ We define this as biotic-abiotic coupling (Figures 1 and 2). Actually, assuming such coupling is implicit to the modeling and mapping of the distribution and abundance of many organisms on Earth as a function of environmental drivers such as mean annual precipitation, temperature, soil texture, $\mathrm{pH}$, etc. Biotic-abiotic coupling is predicted to be a stronger at different taxonomic resolutions (e.g., phylum, class, genus) or at the functional group level (e.g., producers, primary consumers, primary predators, top predators, and detritivores). ${ }^{32,55,66}$ Biotic ecosystem coupling can also be used to evaluate the coordinated/uncoordinated response of interacting constituents of multi-trophic communities to global change. ${ }^{55,67}$ Such interacting constituents may be linked through different types of associations, including mutualisms (e.g., pollination, symbiotic $\mathrm{N}$ fixation, $\mathrm{P}$ mobilization, and habitat modification) determinant of ecosystem structure and functioning than biotic coupling at longer timescales given the prominent role of environmental conditions in controlling the abundance, diversity, and metabolism of species globally. ${ }^{70,71}$ This implies that, in the case of biotic-abiotic connections, when subtle deviations are expected it may be more relevant to look for temporal deviations of a coupled pattern, while evaluating spatial effects may be more suitable for biotic coupling. This may also mean that a loss of biotic-abiotic coupling due to a disturbance or 
A

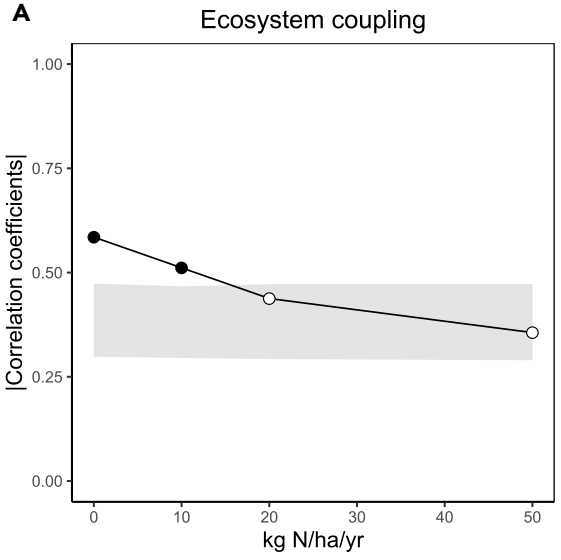

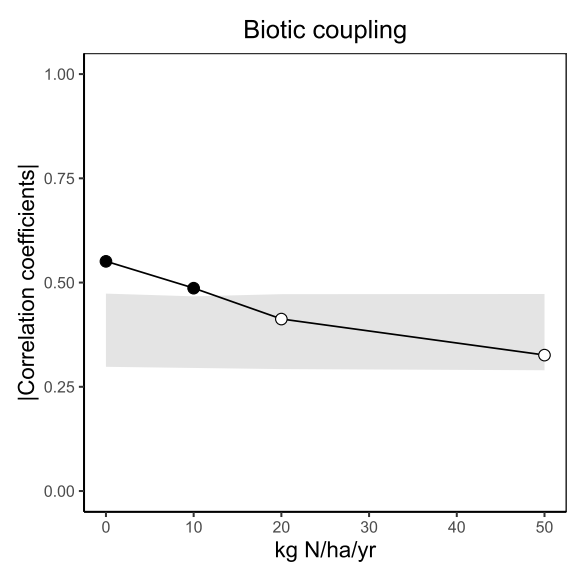

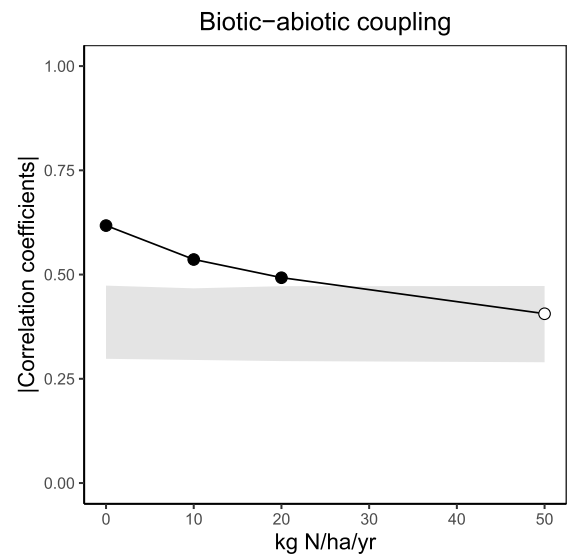

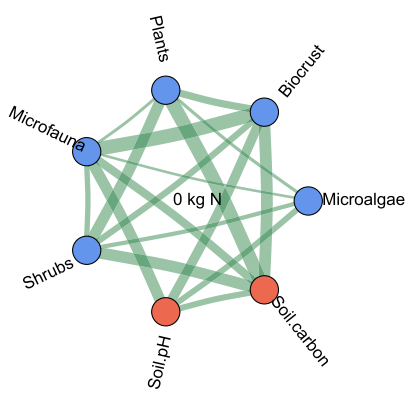
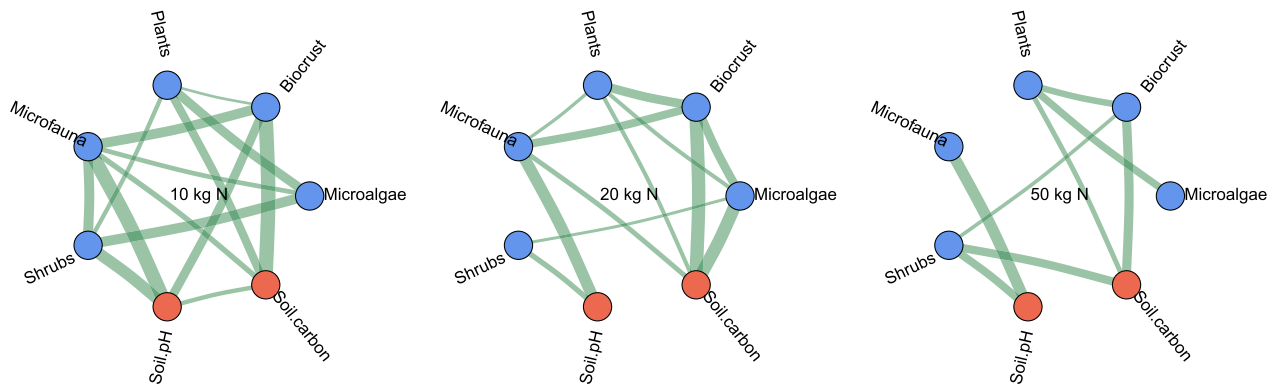

Figure 2. Measuring and representing coupling

Example of changes in ecosystem coupling due to an increase in N deposition based on data published by Ochoa-Hueso. ${ }^{55}$ In the (A), coupling is represented as the average of pairwise Pearson correlations within each $\mathrm{N}$ treatment level. Solid circles indicate $p<0.05$, and open circles indicate $p>0.05$, compared with null models based on 999 random permutations of the same dataset (gray shaded area). In (B), coupling is represented as a undirected network.

stress may have more obvious and sudden implications for the functioning of ecosystems than the loss of biotic coupling, but this has not been formally explored yet. For example, a sudden acidification of soils due to mining drainage will instantaneously have catastrophic effects on the structure, composition, and functioning of ecosystems, while the effects of the loss of biotic interactions due to community mismatches may be more subtle. ${ }^{39}$ In our proposed framework, simply referring to ecosystem coupling means that all biotic and biotic-abiotic couplings are considered simultaneously (Figure 2).

\section{Biogeochemical coupling}

The consensus is unanimous that the global biogeochemical cycles (e.g., C, N, P, S, Si, Ca, K, Mg, and trace elements) are tightly linked through an almost endless range of chemical, physical, and biotic processes, which together drive the functioning of our planet, including the generation of environmental conditions conducive to life itself. ${ }^{72}$ For example, the $\mathrm{C}$ and $\mathrm{P}$ cycles are strongly linked through the process of plant photosynthesis, which fixes atmospheric $\mathrm{CO}_{2}$ and light into energy that is stored into C- and P-rich molecules (i.e., sugars and ATP). ${ }^{72}$ Similarly, the water, $\mathrm{C}$, and mineral cycles are linked through the process of chemical weathering. ${ }^{72}$ Within our proposed framework, biogeochemical coupling means that only spatial and/or temporal relationships among individual chemical elements are evaluated $^{9,54}$ (Figures 1 and 2).
Using our proposed concept of spatial biogeochemical coupling across 16 chronosequences from contrasting biomes with soil ages ranging from centuries to millions of years, Ochoa-Hueso et al. ${ }^{61}$ showed that topsoil element coupling is maintained consistently high (i.e., above the null model envelope) over geological timescales globally. This study also demonstrated that multiple complementary mechanisms contributed to explain this pattern. For example, greater plant richness resulted in the spatial decoupling of topsoil elements, which was attributed to the selective depletion of a range of essential nutrients from soils. ${ }^{73,74}$ Similarly, a greater proportion of fungi compared with bacteria in soils broke the spatial coupling of chemical elements in soils. This was attributed to more developed fungal networks that act as highways for the movement of mineralized elements, ${ }^{75}$ thus redistributing them across the space. In contrast, the content of mineral-free organic matter in soils, thus unprotected from biological decomposition, was associated with more spatially coupled biogeochemical cycles, consistent with the tight stoichiometric control of living organisms on their tissues. ${ }^{76}$ Moreover, Ochoa-Hueso et al. ${ }^{61}$ showed that elements with heavier atomic mass were naturally more decoupled and unpredictable in space than those with lighter mass, and that only the coupling of $\mathrm{C}, \mathrm{N}$, and $\mathrm{P}$ deviated from this predictable pattern, which led these authors to suggest that this anomaly may be an undeniable fingerprint of life in terrestrial soils (Figure 3A). The lack of equilibrium in specific chemical elements and molecules in the atmosphere of planets has been 


\begin{tabular}{|c|c|c|c|c|c|}
\hline \multicolumn{3}{|c|}{$\begin{array}{c}\text { Biotic/biotic- } \\
\text { abiotic/ } \\
\text { References biogeochemical Method }\end{array}$} & \multirow{2}{*}{$\begin{array}{l}\text { Brief description } \\
\text { of method } \\
\text { polynomial } \\
\text { regressions }\end{array}$} & \multirow{2}{*}{$\begin{array}{l}\text { Brief description of } \\
\text { variables considered } \\
\mathrm{N} \text { and } \mathrm{P} \text { contents in } \\
\text { phyto- and zooplankton }\end{array}$} & \multirow{2}{*}{$\begin{array}{l}\text { Main results } \\
\text { the strength of coupling increases } \\
\text { with increasing trophic } \\
\text { state across three large lakes }\end{array}$} \\
\hline 57 & biotic & flow diagrams & & & \\
\hline 58 & biotic & $\begin{array}{l}\text { food-web } \\
\text { modeling }\end{array}$ & $\begin{array}{l}\text { spatially implicit } \\
\text { food-web models }\end{array}$ & trophic groups & $\begin{array}{l}\text { large animals play an } \\
\text { important role contributing } \\
\text { to ecosystem stability }\end{array}$ \\
\hline 55 & $\begin{array}{l}\text { biotic/biotic- } \\
\text { abiotic/ } \\
\text { ecosystem }\end{array}$ & $\begin{array}{l}\text { multiple } \\
\text { pairwise } \\
\text { correlations }\end{array}$ & $\begin{array}{l}\text { mean of correlation/regression } \\
\text { coefficients among axes of } \\
\text { multivariate communities. Mean } \\
\text { of correlation/regression } \\
\text { coefficients between axes of } \\
\text { multivariate communities and } \\
\text { physicochemical properties. } \\
\text { Greater correlation coefficients } \\
\text { reflect greater coupling }\end{array}$ & $\begin{array}{l}\text { axes of multivariate } \\
\text { communities, including } \\
\text { plants, above- and } \\
\text { belowground invertebrates, } \\
\text { and microorganisms; } \\
\text { and soil properties like } \\
\mathrm{pH} \text {, soil organic matter }\end{array}$ & $\begin{array}{l}\mathrm{N} \text { deposition disrupted } \\
\text { (here used as a synonym } \\
\text { for decoupling) the } \\
\text { network of interactions } \\
\text { among biotic and } \\
\text { abiotic constituents }\end{array}$ \\
\hline 31 & $\begin{array}{l}\text { biotic/biotic- } \\
\text { abiotic/ } \\
\text { ecosystem }\end{array}$ & $\begin{array}{l}\text { multiple } \\
\text { pairwise } \\
\text { correlations }\end{array}$ & $\begin{array}{l}\text { mean of correlation/regression } \\
\text { coefficients among axes of } \\
\text { multivariate communities. Mean } \\
\text { of correlation/regression } \\
\text { coefficients between axes of } \\
\text { multivariate communities and } \\
\text { physicochemical properties. } \\
\text { Greater correlation coefficients } \\
\text { reflect greater coupling }\end{array}$ & $\begin{array}{l}\text { axes of multivariate } \\
\text { communities, including } \\
\text { plants, above- and } \\
\text { belowground invertebrates, } \\
\text { and microorganisms; and } \\
\text { soil properties like pH, } \\
\text { soil organic matter, } \\
\text { and bulk density }\end{array}$ & $\begin{array}{l}\text { size-dependent loss of } \\
\text { animals led to altered } \\
\text { couplings. Changes in } \\
\text { functioning were linked } \\
\text { to changes in coupling }\end{array}$ \\
\hline 15 & ecosystem & $\begin{array}{l}\text { gray correlation } \\
\text { matrix }\end{array}$ & $\begin{array}{l}\text { greater correlation reflects } \\
\text { greater coupling }\end{array}$ & $\begin{array}{l}\text { forest stand and } \\
\text { economy-related } \\
\text { variables }\end{array}$ & $\begin{array}{l}\text { coupled forestry } \\
\text { systems are more } \\
\text { economically profitable }\end{array}$ \\
\hline 59 & ecosystem & $\begin{array}{l}\text { coupling } \\
\text { coordination } \\
\text { degree model }\end{array}$ & $\begin{array}{l}\text { calculations of } \\
\text { sequential indices }\end{array}$ & $\begin{array}{l}\text { soil, plant, and } \\
\text { livestock subsystems }\end{array}$ & $\begin{array}{l}\text { diversified restoration practices } \\
\text { are important for ecosystem } \\
\text { coupling and functioning in } \\
\text { degraded alpine meadows }\end{array}$ \\
\hline 27 & biogeochemic & $\begin{array}{l}\text { I stoichiometric } \\
\text { soil ratios }\end{array}$ & pairwise proportions & $\begin{array}{l}\text { total/organic and } \\
\text { available } \mathrm{C}, \mathrm{N} \text {, and } \mathrm{P}\end{array}$ & $\begin{array}{l}\text { stoichiometric ratios change } \\
\text { across a global aridity gradient } \\
\text { due to variations in the } \\
\text { physicochemical and biotic } \\
\text { control across the gradient }\end{array}$ \\
\hline 60 & biogeochemic & $\begin{array}{l}\text { vector length } \\
\text { and angle }\end{array}$ & $\begin{array}{l}\text { length = square root (sqrt) }\left(\mathrm{x}^{2}+\mathrm{y}^{2}\right. \\
\text { Angle = degrees (atan2 }(\mathrm{x}, \mathrm{y})) \\
{ }^{*} \mathrm{x}=\text { relative } \mathrm{C} \text { - vs } \mathrm{P} \text {-acquiring } \\
\text { enzymes; } \mathrm{y}=\text { relative } \mathrm{N} \text { - vs } \\
\mathrm{P} \text {-acquiring enzymes; } \\
\text { atan2 = four-quadrant } \\
\text { inverse tangent }\end{array}$ & $\begin{array}{l}\text { soil ecoenzymes } \\
\text { linked to C:N:P } \\
\text { cycling }\end{array}$ & $\begin{array}{l}\text { the intrinsic linkages of } \\
\text { biological C-, N-, and } \\
\text { P-acquiring enzymes } \\
\text { were broken at the } \\
\text { aridity threshold of } 0.70\end{array}$ \\
\hline 54 & biogeochemic & $\begin{array}{l}\text { multiple pairwise } \\
\text { correlations }\end{array}$ & $\begin{array}{l}\text { mean of Spearman rank } \\
\text { correlations among multiple } \\
\text { (13) chemical elements in } \\
\text { absolute value. Greater } \\
\text { correlation coefficients reflect } \\
\text { greater coupling }\end{array}$ & $\begin{array}{l}\text { available } \\
\text { soil elements }\end{array}$ & $\begin{array}{l}\text { elevated } \mathrm{CO}_{2} \text { decoupled the } \\
\text { characteristic spatial } \\
\text { association pattern among } \\
\text { available chemical elements }\end{array}$ \\
\hline 61 & biogeochemic & $\begin{array}{l}\text { multiple pairwise } \\
\text { correlations }\end{array}$ & $\begin{array}{l}\text { mean of Spearman rank } \\
\text { correlations among multiple } \\
\text { (19) chemical elements in } \\
\text { absolute value. Greater } \\
\text { correlation coefficients reflect } \\
\text { greater coupling }\end{array}$ & total soil elements & $\begin{array}{l}\text { a high level of soil element } \\
\text { coupling was a common } \\
\text { feature in ecosystems across } \\
\text { geological timescales. Atomic } \\
\text { mass and ecological context } \\
\text { (biotic and abiotic) were the } \\
\text { main driving forces of coupling }\end{array}$ \\
\hline
\end{tabular}




\begin{tabular}{|c|c|c|c|c|}
\hline References & $\begin{array}{l}\text { Biotic/biotic- } \\
\text { abiotic/ } \\
\text { biogeochemical Method }\end{array}$ & $\begin{array}{l}\text { Brief description } \\
\text { of method }\end{array}$ & $\begin{array}{l}\text { Brief description of } \\
\text { variables considered }\end{array}$ & Main results \\
\hline 53 & $\begin{array}{l}\text { biogeochemical Earth system } \\
\text { modeling }\end{array}$ & $\begin{array}{l}\text { comparison of } \\
\text { different coupling } \\
\text { assumptions }\end{array}$ & $\begin{array}{l}\mathrm{C}, \mathrm{N} \text {, and } \mathrm{P} \text { pools and } \\
\text { fluxes in plants and soils }\end{array}$ & $\begin{array}{l}\text { the mode of coupling } \\
\text { biogeochemical cycles had } \\
\text { effects on the simulated } \\
\text { biogeochemistry of } \\
\text { ecosystems, and these } \\
\text { varied depending on context } \\
\text { (e.g., succession versus } \\
\text { response to elevated } \mathrm{CO}_{2} \\
\text { concentrations and warming) }\end{array}$ \\
\hline 62 & $\begin{array}{l}\text { biogeochemical community land } \\
\text { model with } \\
\text { prognostic } \\
\mathrm{C} \text { and } \mathrm{N}\end{array}$ & $\begin{array}{l}\text { merging the biophysical } \\
\text { framework of the } \\
\text { community land } \\
\text { model with } \mathrm{C} \text { and } \mathrm{N} \\
\text { dynamics of the } \\
\text { model Biome-BGC }\end{array}$ & $\begin{array}{l}\mathrm{C} \text { and } \mathrm{N} \\
\text { ecosystem pools }\end{array}$ & $\begin{array}{l}\text { considering the close } \\
\text { coupling between } \mathrm{C} \text { and } \mathrm{N} \\
\text { cycles leads to altered } \\
\text { behavior for several critical } \\
\text { feedback mechanisms } \\
\text { operating between the } \\
\text { land biosphere and the } \\
\text { global climate system }\end{array}$ \\
\hline 25 & $\begin{array}{c}\text { biogeochemical stoichiometric } \\
\text { plant ratios }\end{array}$ & $\begin{array}{l}\text { meta-analysis of } \\
\text { multi-element } \\
\text { pairwise proportions }\end{array}$ & $\begin{array}{l}\text { Plant N, P, K, Ca, } \\
\text { Mg, S, Mn, Fe, } \\
\text { and Al contents }\end{array}$ & $\begin{array}{l}\text { Plant element couplings } \\
\text { are affected by soil } \\
\text { nutrient availability and } \\
\text { plant nutrient demand } \\
\text { under climate change }\end{array}$ \\
\hline 26 & $\begin{array}{c}\text { biogeochemical stoichiometric } \\
\text { plant ratios }\end{array}$ & $\begin{array}{l}\text { meta-analysis of } \\
\text { pairwise proportions }\end{array}$ & $\begin{array}{l}\text { Plant } \mathrm{N} \text { and } \\
\mathrm{P} \text { contents }\end{array}$ & $\begin{array}{l}\text { decoupling of the } \mathrm{P} \text { and } \\
\mathrm{N} \text { biogeochemical cycles } \\
\text { in terrestrial plants } \\
\text { under global change }\end{array}$ \\
\hline
\end{tabular}

To be included in this table, authors need to unequivocally refer to the term "coupling" in their studies.

classically proposed as a potential indicator for life elsewhere. ${ }^{77}$ Thus, we speculate that our proposed concept of coupling could also be particularly promising for detecting the fingerprint of life on other planets. ${ }^{61}$ To further introduce this concept, we used published data from Martian regoliths collected by the Sojourner rover from the Mars Pathfinder mission (i.e., 10 elements from six regolith samples) and, very interestingly, we found that the biogeochemical coupling of the evaluated elements followed the expected trend based on the atomic mass of elements (Figure 3B).

Based on our proposed definitions, we posit that our concepts of biotic, biotic-abiotic, and biogeochemical ecosystem couplings go beyond the proportions between two types of organisms (e.g., bacterial/fungal ratios, grasses/forbs ratios), pairwise correlations between organisms, species, and communities, and their physicochemical environment (e.g., soil bacteria and pH), or stoichiometric relationships between two chemical elements (e.g., $\mathrm{C} / \mathrm{N}$ ratio) that have so far often been used to define the coupling of ecological systems in the currently available literature. They do so by allowing us to consider simultaneously multiple pairwise associations that are summarized in a single metric that can then be compared against a null model, which provides an unequivocal reference state. This will allow us to better embrace the complexity of working with multiple elements, physicochemical properties, and organisms in different ecosystems ranging from marine to terrestrial environments. ${ }^{54}$ It is important, however, to understand what such a measure can tell us and what it cannot. In this sense, our integrated index and conceptual framework is designed to give us critical information about how ordered, disordered, or even antiordered a system is compared with a reference state, while it is not designed to distinguish between direct coupling and indirect couplings and/or to detect causative links. Therefore, we suggest that, if coupling is represented as a network (e.g., Figure 2B), it should be visualized as undirected circular networks in which no topological features can be inferred and where the width of connecting lines is proportional to the correlation coefficients.

\section{ECOSYSTEM COUPLING AND FUNCTIONING}

It is generally assumed that more coupled ecosystems have a more efficient processing, cycling, and transfer of energy and matter within and between trophic levels and across ecosystem compartments, ${ }^{79}$ although further investigations are still needed to support this notion within the ecological literature. This may have to do with the fact that ordered states of systems are always able to capture, store, and dissipate more energy than disordered versions of that system, as imposed by the strict laws of thermodynamics. ${ }^{80}$ The implication is that ecosystems with strong coupling may be more sustainable and display a more efficient functioning than less tightly coupled ecosystems. ${ }^{23,66}$ Of course, we acknowledge that weak biotic interactions have previously been identified as important for ecosystem functioning as they can serve as stabilizers of a given 


\section{$\infty$ CellPress}

A

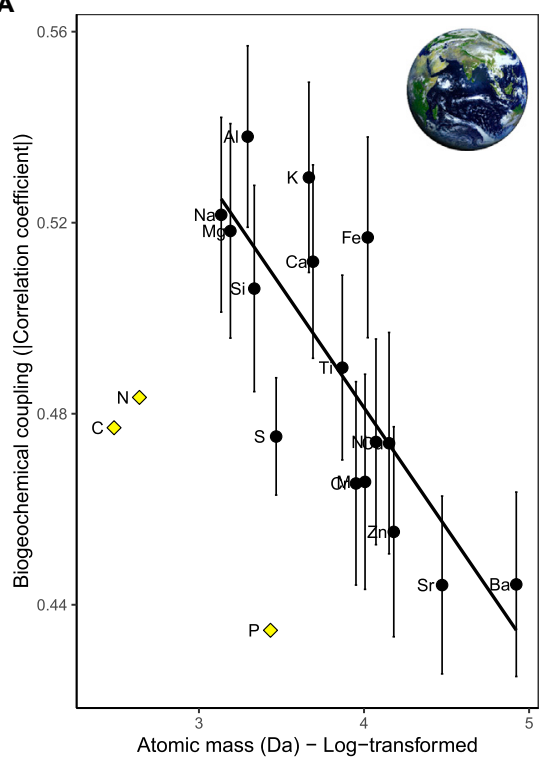

B

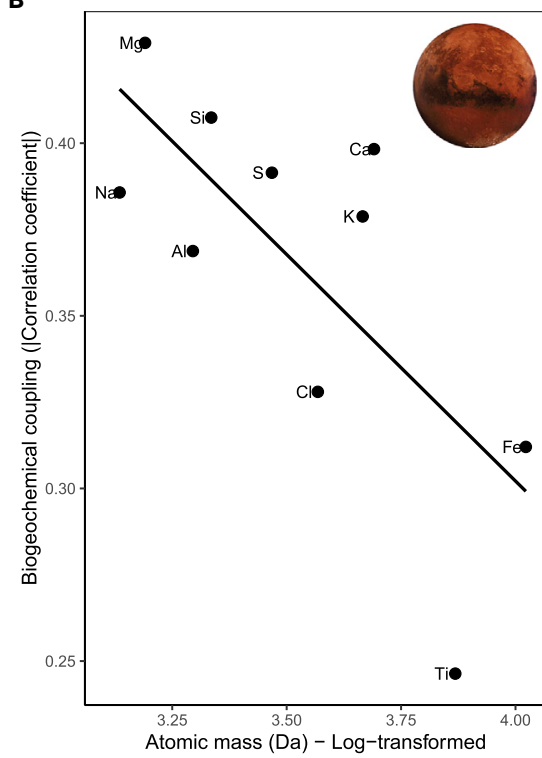

Figure 3. Biogeochemical coupling and atomic mass of elements in Earth soils and Martian regolith

Relationship between atomic mass and element coupling (A) in soils across 16 chronosequences, redrawn using data contained in Ochoa-Hueso et al., ${ }^{61}$ and (B) in Martial regolith analyzed by the Sojourner rover from the Mars Pathfinder mission ${ }^{78}$ $\left(R^{2}=0.44 ; \mathrm{p}=0.02\right)$. In $(\mathrm{A}), \mathrm{C}, \mathrm{N}$, and $\mathrm{P}$ are represented as yellow diamonds, and the solid line is the fitted line for all elements excluding $\mathrm{C}, \mathrm{N}$, and $\mathrm{P}$. The error bars in $(A)$ indicate $95 \%$ confidence interval.

experimental evidence that explicitly supports the importance of ecosystem coupling for ecosystem functioning is currently very limited. ${ }^{31,59,91}$ This can be partially attributed to the scarcity of synchronous, real-world data on a wide range of relevant ecosystem properties and functions sampled with sufficient spatial and/or temporal resolution or, perhaps even more likely, to the lack of a sufficiently integrative framework. Thus, we suggest the potential importance of reconceptualizing some of

community, ${ }^{81-83}$ particularly when communities are dominated by omnivorous species. ${ }^{84}$ However, we argue that tightly coupled ecosystems (i.e., those that are highly structured across space and/or time, as previously defined by the null modeling approach, and that are thus maintained away from entropy) may also be based on weak and/or infrequent direct interactions among organisms of their constituent species.

Coupling, as we define it here, is an emergent property of ecosystems that are connected through the exchange of energy/ matter among the living and non-living parts of the system. This view is, thus, compatible with the importance of weak biotic interactions, which are normally interpreted as such in the context of trophic networks. ${ }^{82,83}$ For example, wolves and aspen do not interact directly, yet their populations are highly structured across space and time due to their strong coupling through the impact of wolves on elk, be it through direct predation or by altering their herd behavior. ${ }^{85}$ Moreover, these trophic and nontrophic impacts of wolves on elk also create soil fertile patches that are non-randomly distributed across the system, either through concentration of urine and dung deposition or through concentration of carcasses, consequently increasing the rate of spatial and temporal heterogeneity, and thus of order, within the system. ${ }^{86}$ The overall coupling of the wolf-elk-aspen-soil system is an important driver of the composition and ecosystem functioning of boreal forests. ${ }^{86,87}$ Thus, we suggest that greater ecosystem coupling within and among communities and their environment may generally lead to more efficient ecosystem functioning.

Investigating the links between the coupling of multiple ecosystem properties and functioning in a changing world is one of the expected fields of research derived from our proposed concept of ecosystem coupling (Figure 4). For example, the loss of the dynamic coupling among soil taxa may coincide with reduced soil $\mathrm{C}$ uptake, ${ }^{66}$ and major leaching of nutrients from ecosystems. ${ }^{88,89}$ This phenomenon is currently the case in high input-output agriculture based on artificial fertilizers and chemical crop protection. ${ }^{88,90}$ However, observational and the currently existing information in the context of our newly proposed framework. ${ }^{45}$ Considering fine-resolution information within an integrative framework and reconceptualization like ours may be essential to detect small changes in ecosystem coupling and functioning that can be the result of anthropogenic disturbances.

For example, a study in subalpine Swiss grasslands applying our concept of ecosystem coupling and its link to functioning demonstrated that those biological communities that were more tightly coupled spatially were also those that had greater $\mathrm{N}$ mineralization and respiration rates. ${ }^{31}$ Similarly, in a study across global drylands, sites characterized by lower functioning had weaker biogeochemical spatial coupling. ${ }^{92}$ However, in the latter study, ${ }^{92}$ spatial coupling was calculated at the global scale due to the lack of within-site spatial replication that would be needed to adequately quantify ecosystem coupling at the site level, as we propose here. Taken together, these two studies provide some of the first insights into how coupling between biotic and abiotic components of ecosystems might affect their functioning. Although empirical validation of the coupling-functioning relationship is still largely lacking, these two examples provide the motivation for proposing that we may be able formulate strategies that promote coupling within ecosystems with the aim of restoring, or even enhancing, their functioning. ${ }^{31,59}$ Moreover, it is likely that not all couplings are equally important for the functioning of ecosystems. ${ }^{24}$ Therefore, identifying keystone connections that maintain coupled ecosystems should be a priority in studies that link the concept of coupling to that of biodiversity-ecosystem functioning.

\section{ECOSYSTEM COUPLING AND GLOBAL ENVIRONMENTAL CHANGE}

Our concept of coupling, highly indicative of how ecosystems are spatially and/or temporally structured, could be particularly useful for the early detection of subtle global change effects on the organization of different elements within and across 


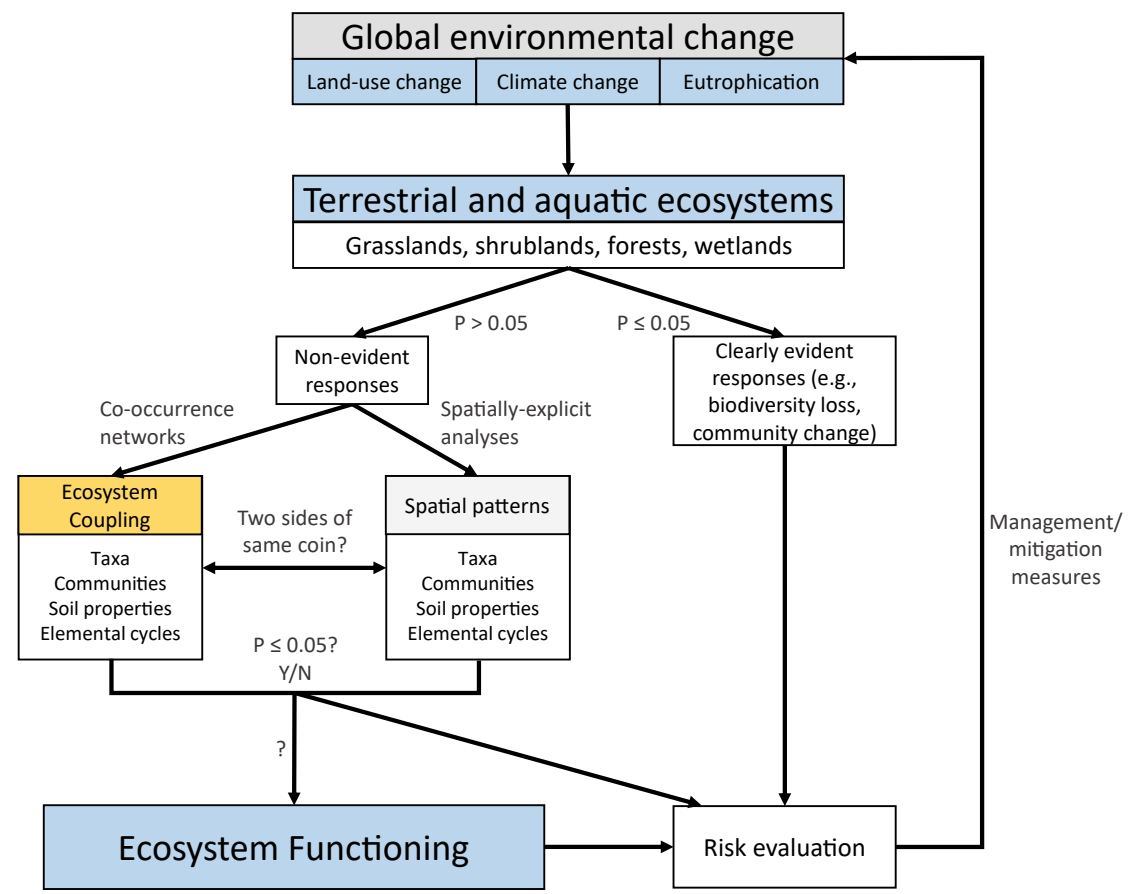

Figure 4. Proposed unified framework for the usefulness of the concept of coupling in global change ecology

erties/constituents, i.e., the history of the ecosystem, which is driven by both evolutionary, filtering, and neutral processes. ${ }^{93}$

Mechanistically, in the case of entire communities, decoupling may be explained by changes in mutualistic and antagonistic connections leading to a change in the presence and/or abundance of individuals. ${ }^{39,94-96}$ This change in connections can further be augmented by altered phenological and behavioral differences, as well as by different sensitivities of the community or ecosystem properties to the new environmental conditions. Loss of coupling between organisms that form above- and belowground food webs, for example as caused by differential responses to climate warming due to their different sensitivities, could be particularly noteworthy. ${ }^{39}$ Of course, the decoupling of ecosystems. ${ }^{24,68}$ As an example, a study in a Mediterranean shrubland reported lack of responses in many ecosystem biotic and abiotic components after 5 years of simulated $\mathrm{N}$ deposition, but it detected a clear loss in coupling of biotic and biotic-abiotic connections $^{55}$ (Figure 2). In this study, considering simultaneously all biotic and biotic-abiotic couplings (i.e., ecosystem coupling) resulted in the clearest pattern. Another study found lower biogeochemical coupling under elevated $\mathrm{CO}_{2}$, despite of the lack of evident effects on nutrient availability. ${ }^{54}$ Interestingly, the authors of the latter study also found that some of the nutrients evaluated, such as $\mathrm{P}$ and $\mathrm{B}$, became more decoupled than what is expected by chance (i.e., anticoupled as defined here) under elevated $\mathrm{CO}_{2}$, although this effect was season dependent. Although the implications of these anticouplings are still poorly explored and understood, we anticipate that this will be a relevant aspect to consider in future ecological research, particularly in the context of the simultaneous evaluation of the different coupling types (i.e., biotic, biotic-abiotic, and biogeochemical).

The easiest interpretation of the loss of coupling of multiple biotic and abiotic variables under global change is that the values of different ecosystem components and properties are moving into different directions in the n-dimensional ecological space, and thus toward a more entropic configuration, in response to disturbance or stress. ${ }^{55}$ Strong responses of particular components of terrestrial ecosystems (e.g., soil $P$ content) to a given global change driver (e.g., $\mathrm{N}$ additions) could also result in important decoupling processes by releasing this element from the control of other biotic and abiotic ecosystem properties. This generally results in a reduced correlation with other biotic and abiotic ecosystem properties and an overall disorder of spatialtemporal dynamics of the ecosystem relative to a control or reference state. ${ }^{54,55}$ The magnitude and trajectory of the response will depend on the initial state of the ecosystem propsome ecosystem constituents may also occur in parallel with the recoupling of other ecosystem constituents, which may not lead to a net loss of coupling. In this case, the main question to address would be whether alternative coupling configurations are able to support comparable rates of ecosystem functioning.

Focusing on how ecosystems are coupled could be particularly useful for experimental ecologists dealing with field-based manipulation experiments in highly spatially and temporally heterogeneous ecosystems, as is often the case. ${ }^{97}$ In addition, the approach of ecosystem coupling may be highly applicable to global change experiments, from nutrient additions and climate change to land-use and agricultural intensification and across markedly different ecosystem types (Boxes 1, 2, and 3; Figure 4). However, systematic evidence for the impacts of global change on ecosystem coupling is still lacking, and it will need to be provided by future synthesis studies aimed at re-evaluating and reconceptualizing the generality in the response of coupling metrics to experimentally manipulated drivers. ${ }^{98,99}$ Experimental networks of local manipulation studies involving nutrients (e.g., Nutrient Network), climate change (e.g., Drought Network), diversity (e.g., TreeDivNet), and disturbance (e.g., DragNet) offer interesting possibilities to test these ideas under a variety of field conditions. ${ }^{24}$ Moreover, given that our proposed framework is based on two characteristics shared by all ecosystems ([1] the biotic, biotic-abiotic, and biogeochemical couplings that are at the core of energy and matter pools and fluxes within ecosystems $^{79,91}$; and [2] that ecosystems are naturally heterogeneous across space and time [i.e., the existence of gradients]), calculating coupling may allow the development of widely applicable and transferable indicators of change that are highly comparable across global change drivers and ecosystem types (Figure 4).

Many of the current consequences of global change are due to low-intensity impacts that accumulate over many years or even 


\section{$\infty$ CellPress}

Box 2. Extending the concept of ecosystem coupling to aquatic systems

In freshwater systems, trophic dynamics may be more tightly coupled than in terrestrial systems thanks to the prominent role of water as a carrier of electrons, protons, and other forms of matter and energy. ${ }^{57}$ For example, species in the detritivore web, such as bacteria and bacterivores, are usually strongly coupled with the herbivore part of the food web (phytoplankton, zooplankton). ${ }^{29}$ Also, different sub-habitats (benthic, riparian, pelagic) are frequently strongly coupled in freshwater systems, both spatially ${ }^{58}$ and temporally. ${ }^{29}$ As a result of these strong temporal and spatial couplings, trophic cascades may be more common in aquatic than in terrestrial systems. Despite these trophic cascades, it is often surprisingly hard to pinpoint how disturbances, such as those from anthropogenic stressors, affect simple metrics of change, such as alpha diversity, abundance, or overall structure and functioning of freshwater systems. ${ }^{100,101}$ Therefore, improved characterization of spatial and temporal coupling metrics in aquatic environments may aid in understanding how dynamic shifts, such as those imposed by anthropogenic stressors, affect the functioning of entire aquatic systems. This requires extensive efforts to monitor the biotic, abiotic, and biogeochemical components of freshwater ecosystems in both a spatial and temporal manner. For example, one study by Barmentlo et al. ${ }^{100}$ showed how such manipulative experiments can be carried out, and how impacts of ubiquitous stressors such as pesticides or eutrophication can act both on the biotic coupling of communities as well as on the functions that are being carried out. This study showed that coupling of aquatic invertebrate communities, evaluated as the percentage of strong correlations of total correlations, can be degraded after the application of an insecticide relative to the control state, even months after the insecticide was removed from the system. ${ }^{100}$ However, the addition of a fertilizer showed an increase in coupling, thus illustrating that the addition of a stressor does not necessarily decrease the coupling within a community in aquatic systems. ${ }^{100}$

decades and that often result in a subtle reordering of communities. ${ }^{114,115}$ Examples of this include the increasing $\mathrm{CO}_{2}$ concentrations in the atmosphere, which has been related to a slow spatial reorganization of understory plant communities in Australian woodlands, ${ }^{116}$ and the continuous deposition of $\mathrm{N}$ in many countries, ${ }^{117}$ which led to a consistent reorganization of communities, soil eutrophication and acidification, and the loss of biodiversity across Europe. ${ }^{118}$ Assessing ecosystem coupling may thus allow us to identify ecosystem changes in response to low-intensity perturbations at a much shorter timescale than when using more classic statistical approaches. This would require manipulation or observational studies including multiple spatial replicates and temporal data points to detect early changes in the organization of ecosystems. Coupling may also contribute to predicting how new evolutionary forces shape the responses of community composition and ecosystem functioning under ongoing global change. ${ }^{119}$

Reconciling short-term versus long-term temporal changes in ecosystem coupling in response to low-intensity perturbations remains challenging. For example, using environmental gradients including multiple temporal or spatial replicates, it could be predicted that, under increasing climatic stress conditions (e.g., drier climates), ecosystems would become increasingly coupled, unless a disruption threshold is eventually crossed and the coupling of the system collapses to a state of less energy/order. ${ }^{120}$ Such increasing coupling preceding the collapse would be a reflection of the greater within-site spatial heterogeneity in terms of soil fertility and plant distribution that typically characterize dryland ecosystems. ${ }^{121}$ Hence, greater coupling at drier sites may be indicative of more energy- and matter-conservative adaptive strategies and also greater mutualism, but not necessarily of greater functioning per se. However, extreme drought or land-use change might also be predicted to have the opposite effect (i.e., sudden decoupling) as a result of short-term multispecies community rearrangements. ${ }^{120}$ This type of sudden loss of coupling between above- and belowground invertebrate communities was indeed shown in an Australian grassland in response to short-term drought. ${ }^{68}$
Whether global change leads to greater or lower coupling may also depend on the nature of the environmental stress. Based on the available evidence so far, we speculate that global changes associated with release of ecological constraints such as nutrient enrichment and elevated $\mathrm{CO}_{2}$ may consistently lead to loss of biotic coupling due to reduced reliance on symbiotic and/or facilitating connections, ${ }^{54,55,122}$ at least in the short term. Moreover, global changes associated with release of ecological constraints may also consistently lead to losses of soil and plant chemical coupling associated with a selective search and depletion of newly limiting resources, including water and nutrients. ${ }^{54,55,122}$ In contrast, global change drivers associated with more stressful conditions such as extreme drought may lead to either greater ecosystem coupling as an adaptive response or to loss of coupling due to a system collapse. Unraveling this is relevant because adapting both highly coupled ecosystems and human societies to rapid environmental changes requires understanding the role of multiple types of biotic, biotic-abiotic, and biogeochemical connections in stabilizing and destabilizing community composition and ecosystem functioning. ${ }^{119,123}$ The way in which ecological communities, environmental properties, chemical elements, and ecosystem processes are spatially and temporally organized may be useful to inform about changes in such coupling. ${ }^{124}$ Moreover, given that energy stores and fluxes within and across ecosystems may be unequivocally linked to their emission pattern of electromagnetic radiation (i.e., the equivalent to an electromagnetic fingerprint), we speculate that the potential evaluation of changes in planetary-level coupling might be best achieved by focusing on how narrow bands of electromagnetic radiation are coupled to one another using spatially explicit satellitederived data.

The systematic evaluation of ecosystem coupling could also be used to detect, and then monitor, when ecosystems change from one stable state to another one. ${ }^{125}$ In fact, it has been suggested that the weakening of ecological connections may result in greater chances of ecosystems transitioning to an alternative stable state. ${ }^{64,69,120}$ This also has promising implications in 
Box 3. Using the concept of coupling to bridge the gap between terrestrial ecosystems and human health

The concept of holobiont organisms make human beings true living ecosystems in which the approximately one billion eukaryotic cells that form part of our bodies and the approximately 10 billion microbial cells that live in and on us are deeply interlinked. ${ }^{102}$ This also applies to any other multicellular species, including plant ${ }^{103}$ and animal species. ${ }^{104}$ Moreover, we know that human well-being is linked to the correct functioning of these microbial communities, which help us, for example, to digest the food we eat and to produce certain vitamins and hormones. ${ }^{105,106}$ Thus, if it were of universal applicability, the concept of coupling, in turn intimately linked to the concepts of order and energy/matter fluxes, should also apply to such living ecosystems and their state of health/disease. The fact that the word disorder is frequently used as a synonym of disease is highly evocative of this parallelism. Supporting this, recent studies have suggested that Alzheimer and other neurodegenerative dementias may not be a brain disease but a progressive system-level network disorder by chronic network stress and dyshomeostasis, ${ }^{107,108}$ including the dysregulation of (the biochemical coupling of) transition metals such as $\mathrm{Fe}, \mathrm{Cu}$, and $\mathrm{Zn} .{ }^{109}$ This dysregulation may actually be linked to air pollution and other environmental stresses ${ }^{110}$ in a similar way by which air pollution can decouple ecosystems. Moreover, there is also compelling evidence of the role of the loss of coupling of microbial communities inhabiting the human gut as a mechanism to explain the overall malfunctioning of the human body. This includes dysbiosis associated with changes in the relative abundance of Bacteroidetes versus Firmicutes, which is a well-established indicator of obesity and type 2 diabetes. ${ }^{105,106,111}$ Such deviations are usually reported in the form of altered microbial ratios, but we speculate that they may actually be better evaluated in the form of an altered spatiotemporal coupling between the two phyla (i.e., Bacteroidetes versus Firmicutes), or, perhaps even better, of the two phyla in relation to the rest of the dominant bacterial phyla found within our guts, which may provide the reference state to compare with. Other diseases that may be particularly linked to decoupling are multiple sclerosis ${ }^{112}$ and cancer. ${ }^{113}$ Cancer, for example, has been associated with higher levels of intracellular (i.e., cytoskeletal) disorganization. Thus, we suggest that our spatial and temporal ecosystem coupling approach could help us to better detect subtle changes in the functioning of the human body and to establish quick and successful early-response measures. For example, sequential blood/feces tests analyzed within our proposed framework of temporal coupling may reveal important maladjustments in the metabolism of sick patients that otherwise may go undetected when test values are solely checked against a predefined range. If this were true, it would mean that we could also look for strategies that promote coupling within our own organisms; for example, through the identification and manipulation of generalist and specialist microbial couplers that could take the form of a next generation of probiotics. The main difference would be that these microbial strains would be selected based on their ability to recouple our bodies, a feature that is actually known to be critical for an efficient metabolic functioning, and not necessarily only based on their specific metabolic functions. Strikingly similar to this suggestion, it has been suggested that a better understanding of the network of interactions leading to tumorigenesis may lead to the next generation of cancer treatments aimed not necessarily at killing the cancer but at restoring the natural order and tissue function. ${ }^{113}$

restoration practices such as topsoil removal that deliberately disrupt ecological connections allowing the reassembly of networks and biogeochemical processes, initiating a transition toward a potentially more ecologically coupled, and thus energetically efficient, target state. ${ }^{126,127}$ Here the key concept would be adaptation through relaxation. In other words, some couplings within the system are relaxed by topsoil removal, and that allows the self-reconfiguration of the system toward the desired configuration, which may involve the favoring of preferential energy pathways. In the case of sustainable agroecosystems, a greater soil biogeochemical and biotic coupling may mean greater productivity and protection against pests and diseases through a more reliable supply of a range of essential nutrients from recycled organic matter, greater photosynthesis, and a more developed network of fungal hyphae and natural enemies. ${ }^{128}$

\section{RECOUPLING ECOSYSTEMS TO RESTORE FUNCTIONING: A HYPOTHESIS ON ECOSYSTEM RESILIENCE}

Life can be broadly defined by its unique ability to create more life from itself, its astonishing ability to self-organize and reassemble through the creation of new interactions and links, and to evolve. This is all connected to the incessant flow of electrons through redox gradients across the Earth ecosystems.
Thus, a key question about life from the perspective of coupling is how the spontaneous recoupling and spatiotemporal reorganization of previously decoupled ecosystems takes place once the disturbance or environmental stress stops. We refer to this as ecosystem coupling resilience, which we define as the ability of ecosystem properties and organisms to reconnect with each other after a given disturbance. Hence, a potential path to prevent or modify the outcome of undesired transitions in stressed ecosystems could involve the promotion of certain key ecological and biogeochemical couplings that could help land or conservation managers to pull such endangered systems away from their critical boundaries ${ }^{129}$ (Figure 4).

We may also potentially be able to restore degraded ecosystems to desirable levels of biotic, biotic-abiotic, and biogeochemical coupling by favoring certain spatially ordered patterns toward a more efficient capture, flow, and storage of energy and matter, thus increasing both the resistance and resilience of ecosystems against undesired state changes. ${ }^{79,124}$ Different measures could be applied to steer the recovery of ecosystem coupling and to favor more functional spatial patterns. As a general rule, such measures should likely involve the creation of gradients that spontaneously drive the flux of energy and matter (and thus of electrons) across the gradient. In turn, this would create other gradients, thus reactivating the spontaneous recovery loop. More specifically, greater ecosystem coupling in 


\section{CellPress}

drylands may be favored by inoculating microbial communities with a greater ability to produce extracellular polysaccharides. ${ }^{130}$ This greater coupling may also contribute to create a more densely connected network of hyphae ${ }^{131}$ in what is known as the fungal loop. ${ }^{130}$ More fungal biomass has also been associated with a greater ability of plants to generate islands of fertility underneath them in drylands worldwide. ${ }^{132}$ These islands are known for their importance to maintain high levels of biodiversity in harsh environments and to speed up ecosystem recovery, ${ }^{132}$ while the presence of shrubs is also linked to the characteristic spatial and functional pattern of drylands. ${ }^{92}$ Likewise, in aquatic ecosystems, recovery of ecosystems from the negative effects of insecticides has been associated recently with the restoration of coupling. ${ }^{100}$

Ecosystem coupling promoting microbiome inoculation may be particularly well suited to restoring degraded ecosystems, such as abandoned open-air mines, sites exposed to heavy pollution, and/or in places where wars and/or weapon testing have affected the landscape. The ability to seed the fast recovery of ecosystems with the inoculation of microbial and invertebrate communities, thereby speeding up ecosystem and biogeochemical coupling, may also be particularly useful in places where massive land clearing has set the ecosystem for greater risk of suffering floods or landslides. Moreover, our proposed concept of coupling may also be useful to speed up the transition from agrochemical-based to nature-based sustainable farming, thus reducing the time to convert conventional into a more organic, or regenerative, type of agriculture. ${ }^{14}$ Similarly, it has also been suggested that more tightly coupled forest plantations may be more ecologically and economically sustainable than conventional decoupled ones. ${ }^{15}$ Whether coupling-promoting inoculation can improve aquatic ecosystem coupling has not been studied to date, but the positive examples from other systems show its potential and thus may require further exploration (Box 2). However, implementing all this would require mechanistic understanding of how, why, and under what circumstances parallel changes in ecosystem coupling and spatial patterns determine changes in the behavior of ecosystems and what this means in terms of energy flux (i.e., functioning; Figure 4). The urgency to act in the context of the current planetary environmental challenges means that time is now ripe to combine the integrative approach proposed here with practical restoration and regeneration programs to define functional coupling levels while at the same time contributing to developing mechanistic theory that links all types of couplings (i.e., biotic, biotic-abiotic, and biogeochemical) to functioning. ${ }^{59}$

Using the concept of coupling to assess the recovery of ecosystems calls for the identification of organisms or groups of organisms with special abilities to reconnect ecosystems under general or particular environmental conditions. ${ }^{13,133}$ We define these organisms as specialist and generalist couplers, respectively. These may be a special type of ecosystem engineers, ${ }^{69,134}$ keystone taxa, ${ }^{89}$ and/or foundation species. ${ }^{135}$ The identification of such taxa may be achieved more effectively through a combination of field- and laboratory-based approaches. ${ }^{13}$ Certain actinobacterial and mycorrhizal strains, ${ }^{136-139}$ or even nematode, ${ }^{32,140}$ and protistan ${ }^{34,141}$ taxa may be candidates as specialist and generalist couplers. We may also be able to identify certain types of biotic-abiotic connections that are particu- larly needed to boost the recovery of system-level coupling. This may involve the inoculation of ecosystems with specialist and generalist microbial couplers along with dead organic matter mixed with expandable clay minerals (e.g., bentonites, montmorillonites), which are known to promote key ecosystem functions such as $\mathrm{N}$ mineralization and nutrient conservation, ${ }^{72,142}$ as well as to enhance the viability of added microbes. ${ }^{143}$ Moreover, these inoculants could be added along with seeds from the desired target plant communities. Ideally, once they become established, these communities along with their functional and structural properties should be able to self-propagate across entire ecosystems, thus boosting coupling and recovery. Monitoring the coupling of these incipient interactions could also be a way to investigate the success of ecosystem restoration. Although, for obvious reasons, the texture and organic matter content of soils will not instantly change due to the inoculation, a positive feedback loop may occur leading to enhanced $\mathrm{C}$ fixation due to plant photosynthesis, clay-forming weathering due to active microbial life-mineral interactions, and finally $C$ stabilization. ${ }^{144}$ Such $\mathrm{C}$ stabilization and formation of humic substances may, in turn, promote the growth of the inoculated microbial couplers, hence reinforcing the positive loop.

\section{CONCLUSIONS AND FURTHER CHALLENGES}

Here, we started paving the way toward a unifying framework for the concept of coupling in ecology, whose use was previously widespread but poorly defined, and proposed that the changes in the spatial and temporal coupling of biotic, bioticabiotic, and biogeochemical connections may be a universal and predictive measure of Earth ecosystems experiencing stress, including that originated from global change impacts. However, our coupling metrics, based on system-level correlations in absolute value, are likely highly influenced by the spatiotemporal scale of analysis, and may thus benefit from the simultaneous consideration of different scales, as represented by correlograms. We also define three coupling states of ecosystems based on a null modeling approach: (1) coupled, (2) decoupled, and (3) anticoupled. Moreover, we suggest that these changes in coupling, which are inextricably linked to alterations in the spatial and temporal patterns of ecosystems, and thus to how ecosystems are ordered/disordered, should be linked to shifts in ecosystem functioning (i.e., fluxes of energy and matter). Based on its universality, we speculate that our coupling concept could also be translated to a range of disciples, from medicine (Box 3 ) to planetary science, where it could be used to investigate the fingerprint of life elsewhere. Most importantly, this new framework will allow us to understand the causes of order/disorder across ecosystems and thus help us to develop and apply the right tools to restore the health and functioning of Earth ecosystems.

\section{ACKNOWLEDGMENTS}

R.O.-H. is financially supported by the Ramón y Cajal program from the MICINN (RYC-2017 22032) and projects (PID2019-106004RA-I00). R.O.-H. is also thankful to Dr. Lilia Serrano-Grijalva for useful discussions. M.D.-B. is supported by a Ramón y Cajal grant from the Spanish Government (RYC2018025483-I). M.C.R. was supported by the Swiss National Science Foundation grant no.31003A_166654. The authors declare no competing interests. 


\section{REFERENCES}

1. Sala, O.E., Chapin, F.S., Armesto, J.J., Berlow, E., Bloomfield, J., Dirzo, R., Huber-Sanwald, E., Huenneke, L.F., Jackson, R.B., Kinzig, A., et al. (2000). Global biodiversity scenarios for the year 2100. Science 287 1770-1774.

2. Rillig, M.C., Ryo, M., Lehmann, A., Aguilar-Trigueros, C.A., Buchert, S., Wulf, A., Iwasaki, A., Roy, J., and Yang, G. (2019). The role of multiple global change factors in driving soil functions and microbial biodiversity. Science 366, 886-890.

3. Dakos, V., Carpenter, S.R., van Nes, E.H., and Scheffer, M. (2015). Resilience indicators: prospects and limitations for early warnings of regime shifts. Philos. Trans. R. Soc. B Biol. Sci. 370. https://doi.org/10.1098/ rstb.2013.0263.

4. Valiente-Banuet, A., Aizen, M.A., Alcántara, J.M., Arroyo, J., Cocucci, A., Galetti, M., García, M.B., García, D., Gómez, J.M., Jordano, P., et al (2015). Beyond species loss: the extinction of ecological interactions in a changing world. Funct. Ecol. 29, 299-307.

5. Tylianakis, J.M., Didham, R.K., Bascompte, J., and Wardle, D.A. (2008) Global change and species interactions in terrestrial ecosystems. Ecol. Lett. 11, 1351-1363.

6. Barnosky, A.D., Hadly, E.A., Bascompte, J., Berlow, E.L., Brown, J.H., Fortelius, M., Getz, W.M., Harte, J., Hastings, A., Marquet, P.A., et al (2012). Approaching a state shift in Earth's biosphere. Nature 486, 52-58.

7. Stankovski, T., Pereira, T., McClintock, P.V.E., and Stefanovska, A. (2017). Coupling functions: universal insights into dynamical interaction mechanisms. Rev. Mod. Phys. 89, 45001.

8. Gillespie, D.T. (1977). Exact stochastic simulation of coupled chemical reactions. J. Phys. Chem. 81, 2340-2361.

9. Schlesinger, W.H., Cole, J.J., Finzi, A.C., and Holland, E.A. (2011). Introduction to coupled biogeochemical cycles. Front. Ecol. Environ. 9, 5-8.

10. Bier, M., and Kostur, M. (2000). Nonlinearly coupled chemical reactions. In Stochastic Processes in Physics, Chemistry, and Biology, J.A. Freund and T. Pöschel, eds. (Springer Berlin Heidelberg), pp. 32-37.

11. Barnes, A.D., Jochum, M., Lefcheck, J.S., Eisenhauer, N., Scherber, C. O'Connor, M.I., de Ruiter, P., and Brose, U. (2018). Energy flux: the link between multitrophic biodiversity and ecosystem functioning. Trends Ecol. Evol. 33, 186-197.

12. Wubs, E.R.J., van der Putten, W.H., Bosch, M., and Bezemer, T.M (2016). Soil inoculation steers restoration of terrestrial ecosystems. Nat. Plants 2, 16107.

13. Toju, H., Peay, K.G., Yamamichi, M., Narisawa, K., Hiruma, K., Naito, K., Fukuda, S., Ushio, M., Nakaoka, S., Onoda, Y., et al. (2018). Core microbiomes for sustainable agroecosystems. Nat. Plants 4, 247-257.

14. Bender, S.F., Wagg, C., and van der Heijden, M.G.a. (2016). An underground revolution: biodiversity and soil ecological engineering for agricultural sustainability. Trends Ecol. Evol. 31, 440-452.

15. Dong, P.W., Zhuang, S.Y., Lin, X.H., and Zhang, X.Z. (2013). Economic evaluation of forestry industry based on ecosystem coupling. Math. Comput. Model. 58, 1010-1017.

16. Bailleul, B., Berne, N., Murik, O., Petroutsos, D., Prihoda, J., Tanaka, A Villanova, V., Bligny, R., Flori, S., Falconet, D., et al. (2015). Energetic coupling between plastids and mitochondria drives $\mathrm{CO}_{2}$ assimilation in diatoms. Nature 524, 366-369.

17. de Sousa, M.C., Marcus, F.A., Caldas, I.L., and Viana, R.L. (2018). Energy distribution in intrinsically coupled systems: the spring pendulum paradigm. Phys. A. Stat. Mech. Its Appl. 509, 1110-1119.

18. Maithreye, R., and Sinha, S. (2004). Modelling simple biochemical networks. In Function and Regulation of Cellular Systems, A. Deutsch, J. Howard, M. Falcke, and W. Zimmermann, eds. (Birkhäuser Basel)), pp. 251-257.

19. Huang, H., Xue, Y., Chilukoti, N., Liu, Y., Chen, G., and Diallo, I. (2020). Assessing global and regional effects of reconstructed land-use and land-cover change on climate since 1950 using a coupled land-atmosphere-ocean model. J. Clim. 33, 8997-9013.

20. Lindeman, R. (1942). The trophic-dynamic aspect of ecology. Ecology 23, 399-417.

21. Odum, E.P. (1969). The strategy of ecosystem development. Science $164,262-270$

22. Körner, C., and Spehn, E. (2019). A Humboldtian view of mountains. Science 365, 1061.

23. Heleno, R., Garcia, C., Jordano, P., Traveset, A., Gómez, J.M., Blüthgen, N., Memmott, J., Moora, M., Cerdeira, J., Rodríguez-Echeverría, S., et al. (2014). Ecological networks: delving into the architecture of biodiversity. Biol. Lett. 10, 4-6.
24. Ings, T.C., Montoya, J.M., Bascompte, J., Blüthgen, N., Brown, L., Dormann, C.F., Edwards, F., Figueroa, D., Jacob, U., Jones, J.I., et al. (2009). Ecological networks - beyond food webs. J. Anim. Ecol. 78, 253-269.

25. Tian, D., Reich, P.B., Chen, H.Y.H., Xiang, Y., Luo, Y., Shen, Y., Meng, C. Han, W., and Niu, S. (2019). Global changes alter plant multi-element stoichiometric coupling. New Phytol. 221, 807-817.

26. Yuan, Z.Y., and Chen, H.Y.H. (2015). Decoupling of nitrogen and phosphorus in terrestrial plants associated with global changes. Nat. Clim. Chang. 5, 465-469.

27. Delgado-Baquerizo, M., Maestre, F.T., Gallardo, A., Bowker, M.a., Wallenstein, M.D., Quero, J.L., Ochoa, V., Gozalo, B., García-Gómez, M., Soliveres, S., et al. (2013). Decoupling of soil nutrient cycles as a function of aridity in global drylands. Nature 502, 672-676.

28. Finzi, A.C., Austin, A.T., Cleland, E.E., Frey, S.D., Houlton, B.Z., and Wallenstein, M.D. (2011). Responses and feedbacks of coupled biogeochemical cycles to climate change: examples from terrestrial ecosystems. Front. Ecol. Environ. 9, 61-67.

29. Schindler, D.E., and Scheuerell, M.D. (2002). Habitat coupling in lake ecosystems. Oikos 98, 177-189.

30. Weitere, M., Erken, M. Majdi, N., Arndt, $\mathrm{H}$., Norf, $\mathrm{H}$., Reinshagen, M Traunspurger, W., Walterscheid, A., and Wey, J.K. (2018). The food web perspective on aquatic biofilms. Ecol. Monogr. 88, 543-559.

31. Risch, A.C., Ochoa-Hueso, R., van der Putten, W.H., Bump, J.K., Busse M.D., Frey, B., Gwiazdowicz, D.J., Page-Dumroese, D.S., Vandegehuchte, M.L., Zimmermann, S., et al. (2018). Size-dependent loss of aboveground animals differently affects grassland ecosystem coupling and functions. Nat. Commun. 9, 3684.

32. Wubs, E.R.J., van der Putten, W.H., Mortimer, S.R., Korthals, G.W., Duyts, H., Wagenaar, R., and Bezemer, T.M. (2019). Single introductions of soil biota and plants generate long-term legacies in soil and plant community assembly. Ecol. Lett. 22, 1145-1151.

33. Chapin, F.S. (1980). The mineral nutrition of wild plants. Annu. Rev. Ecol. Syst. 11, 233-260.

34. Paterson, E. (2003). Importance of rhizodeposition in the coupling of plant and microbial productivity. Eur. J. Soil Sci. 54, 741-750.

35. Bell, C., Carrillo, Y., Boot, C.M., Rocca, J.D., Pendall, E., and Wallenstein, M.D. (2013). Rhizosphere stoichiometry: are C:N:P ratios of plants, soils, and enzymes conserved at the plant species-level? New Phytol. 201, 505-517.

36. Fierer, N., and Jackson, R.B. (2006). The diversity and biogeography of soil bacterial communities. Proc. Natl. Acad. Sci. U S A 103, 626-631.

37. Fierer, N. (2017). Embracing the unknown: disentangling the complexities of the soil microbiome. Nat. Rev. Microbiol. 15, 579-590.

38. Fierer, N., Leff, J.W., Adams, B.J., Nielsen, U.N., Bates, S.T., Lauber, C.L., Owens, S., Gilbert, J.A., Wall, D.H., and Caporaso, J.G. (2012) Cross-biome metagenomic analyses of soil microbial communities and their functional attributes. Proc. Natl. Acad. Sci. U S A 109, 21390-21395.

39. Thakur, M.P. (2020). Climate warming and trophic mismatches in terres trial ecosystems: the green-brown imbalance hypothesis. Biol. Lett. $16,20-22$.

40. de Vries, F.T., Thébault, E., Liiri, M., Birkhofer, K., Tsiafouli, M.a., Bjørnlund, L., Bracht Jørgensen, H., Brady, M.V., Christensen, S., de Ruiter, P.C., et al. (2013). Soil food web properties explain ecosystem services across European land use systems. Proc. Natl. Acad. Sci. U. S. A. 110 $14296-14301$.

41. Guttal, V., and Jayaprakash, C. (2008). Changing skewness: an early warning signal of regime shifts in ecosystems. Ecol. Lett. 11, 450-460.

42. Clements, C.F., and Ozgul, A. (2018). Indicators of transitions in biological systems. Ecol. Lett. 21, 905-919.

43. Pringle, R.M., and Tarnita, C.E. (2017). Spatial self-organization of ecosystems: integrating multiple mechanisms of regular-pattern formation Annu. Rev. Entomol. 62, 359-377.

44. Dyke, J.G., and Weaver, I.S. (2013). The emergence of environmental homeostasis in complex ecosystems. PLoS Comput. Biol. 9, e1003050.

45. Kurakin, A. (2011). The self-organizing fractal theory as a universal dis covery method: the phenomenon of life. Theor. Biol. Med. Model. 8, 4.

46. West, G.B., and Brown, J.H. (2005). The origin of allometric scaling laws in biology from genomes to ecosystems: towards a quantitative unifying theory of biological structure and organization. J. Exp. Biol. 208, 1575-1592.

47. Waring, S. (2018). Quantum biology: a scientific revolution in our under standing of biological systems. Biol. Syst. Open Access 7, 1-8. 
48. Sexton, J.P., Montiel, J., Shay, J.E., Stephens, M.R., and Slatyer, R.A. (2017). Evolution of ecological niche breadth. Annu. Rev. Ecol. Evol. Syst. 48, 183-206.

49. HilleRisLambers, J., Adler, P.B., Harpole, W.S., Levine, J.M., and Mayfield, M.M. (2012). Rethinking community assembly through the lens of coexistence theory. Annu. Rev. Ecol. Evol. Syst. 43, 227-248.

50. McGill, B.J., Enquist, B.J., Weiher, E., and Westoby, M. (2006). Rebuilding community ecology from functional traits. Trends Ecol. Evol. 21, 178-185.

51. Bertness, M.D., Leonard, G.H., Levine, J.M., Schmidt, P.R., and Ingraham, A.O. (1999). Testing the relative contribution of positive and negative interactions in rocky intertidal communities. Ecology 80, 2711-2726.

52. Goudard, A., and Loreau, M. (2008). Nontrophic interactions, biodiversity, and ecosystem functioning: an interaction web model. Am. Nat. 171, 91-106.

53. Rastetter, E.B. (2011). Modeling coupled biogeochemical cycles. Front. Ecol. Environ. 9, 68-73.

54. Ochoa-Hueso, R., Piñeiro, J., and Power, S.A. (2019). Decoupling of nutrient cycles in a Eucalyptus woodland under elevated $\mathrm{CO}_{2}$. J. Ecol. 107, 2532-2540.

55. Ochoa-Hueso, R. (2016). Nonlinear disruption of ecological interactions in response to nitrogen deposition. Ecology 97, 2802-2814.

56. Tjøstheim, D. (1978). A measure of association for spatial variables. Biometrika 65, 109-114.

57. Carney, H.J., and Elser, J.J. (1990). Strength of zooplankton-phytoplankton coupling in relation to lake trophic state BT - large lakes: ecological structure and function. In Large Lakes, M.M. Tilzer and C. Serruya, eds. (Springer Berlin Heidelberg), pp. 615-631.

58. McCann, K.S., Rasmussen, J.B., and Umbanhowar, J. (2005). The dynamics of spatially coupled food webs. Ecol. Lett. 8, 513-523.

59. Wang, Y., Sun, Y., Chang, S., Wang, Z., Fu, H., Zhang, W., and Hou, F. (2020). Restoration practices affect alpine meadow ecosystem coupling and functions. Rangel. Ecol. Manag. 73, 441-451.

60. Feng, J., Wei, K., Chen, Z., Xiaotao, L., Tian, J., Wang, C., and Chen, L. (2019). Coupling and decoupling of soil carbon and nutrient cycles across an aridity gradient in the drylands of northern China: evidence from ecoenzymatic stoichiometry. Glob. Biogeochem. Cycles 33, 559-569.

61. Ochoa-Hueso, R., Plaza, C., Moreno-Jiménez, E., and Delgado-Baquerizo, M. (2021). Soil element coupling is driven by ecological context and atomic mass. Ecol. Lett. 24, 319-326.

62. Thornton, P.E., Lamarque, J.-F., Rosenbloom, N.A., and Mahowald, N.M. (2007). Influence of carbon-nitrogen cycle coupling on land model response to $\mathrm{CO}_{2}$ fertilization and climate variability. Glob. Biogeochem. Cycles 21, GB4018.

63. Holzer, J.M., Carmon, N., and Orenstein, D.E. (2018). A methodology for evaluating transdisciplinary research on coupled socio-ecological systems. Ecol. Indic. 85, 808-819.

64. Bardgett, R.D., and Caruso, T. (2020). Soil microbial community responses to climate extremes: resistance, resilience and transitions to alternative states. Philos. Trans. R. Soc. B Biol. Sci. 375, 20190112.

65. Saint-Béat, B., Baird, D., Asmus, H., Asmus, R., Bacher, C., Pacella, S.R., Johnson, G.A., David, V., Vézina, A.F., and Niquil, N. (2015). Trophic networks: how do theories link ecosystem structure and functioning to stability properties? A review. Ecol. Indic. 52, 458-471.

66. Morriën, E., Hannula, S.E., Snoek, L.B., Helmsing, N.R., Zweers, H., de Hollander, M., Soto, R.L., Bouffaud, M., Buée, M., Dimmers, W., et al. (2017). Soil networks become more connected and take up more carbon as nature restoration progresses. Nat. Commun. 8, 14349.

67. de Vries, F.T., Grif, R.I., Bailey, M., Craig, H., Girlanda, M., Gweon, H.S., Hallin, S., Kaisermann, A., Keith, A.M., Kretzschmar, M., et al. (2018). Soil bacterial networks are less stable under drought than fungal networks. Nat. Commun. 9, 3033.

68. Torode, M.D., Barnett, K.L., Facey, S.L., Nielsen, U.N., Power, S.A., and Johnson, S.N. (2016). Altered precipitation impacts on above-and belowground grassland invertebrates: summer drought leads to outbreaks in spring. Front. Plant Sci. 7, 1468.

69. Byers, J.E., Cuddington, K., Jones, C.G., Talley, T.S., Hastings, A., Lambrinos, J.G., Crooks, J.A., and Wilson, W.G. (2006). Using ecosystem engineers to restore ecological systems. Trends Ecol. Evol. 21, 493-500.

70. Benton, M.J. (2009). The red queen and the court jester: species diversity and the role of biotic and abiotic factors through time. Science 323 , 728-732.
71. Sommer, B., Harrison, P.L., Beger, M., and Pandolfi, J.M. (2014). Traitmediated environmental filtering drives assembly at biogeographic transition zones. Ecology 95, 1000-1009.

72. Schlesinger, W.H., and Bernhardt, E. (2020). Biogeochemistry. An Analysis of Global Change 4th Editio (Academic Press).

73. Rumpel, C., and Chabbi, A. (2019). Plant-soil interactions control CNP coupling and decoupling processes in agroecosystems with perennial vegetation. In Agroecosystem Diversity: Reconciling Contemporary Agriculture and Environmental Quality, Gilles Lemaire, Paulo Carvalho, Scott Kronberg, and Sylvie Recous, eds. (Elsevier Inc.), pp. 3-13.

74. Lambers, H., Brundrett, M.C., Raven, J.A., and Hopper, S.D. (2010). Plant mineral nutrition in ancient landscapes: high plant species diversity on infertile soils is linked to functional diversity for nutritional strategies. Plant Soil 334, 11-31.

75. Allen, M.F. (2007). Mycorrhizal fungi: highways for water and nutrients in arid soils. Vadose Zo. J. 6, 291-297.

76. Sardans, J., Rivas-Ubach, A., and Peñuelas, J. (2011). The elemental stoichiometry of aquatic and terrestrial ecosystems and its relationships with organismic lifestyle and ecosystem structure and function: a review and perspectives. Biogeochemistry 111, 1-39.

77. Stolz, J.F. (2016). Gaia and her microbiome. FEMS Microbiol. Ecol 93, fiw247.

78. Bell, J.F., III, McSween, H.Y., Jr., Crisp, J.A., Morris, R.V., Murchie, S.L., Bridges, N.T., Johnson, J.R., Britt, D.T., Golombek, M.P., Moore, H.J., et al. (2000). Mineralogic and compositional properties of Martian soil and dust: results from Mars pathfinder. J. Geophys. Res. Planets 105, 1721-1755.

79. Soininen, J., Bartels, P., Heino, J., Luoto, M., and Hillebrand, H. (2015). Toward more integrated ecosystem research in aquatic and terrestrial environments. Bioscience 65, 174-182.

80. Schneider, E.D., and Kay, J.J. (1994). Complexity and thermodynamics: towards a new ecology. Futures 26, 626-647.

81. Berlow, E.L. (1999). Strong effects of weak interactions in ecological communities. Nature 398, 330-334.

82. Kadoya, T., and McCann, K.S. (2015). Weak interactions and instability cascades. Sci. Rep. 5, 12652

83. McCann, K., Hastings, A., and Huxel, G.R. (1998). Weak trophic interactions and the balance of nature. Nature 395, 794-798.

84. Emmerson, M., and Yearsley, J.M. (2004). Weak interactions, omnivory and emergent food-web properties. Proc. R. Soc. Lond. Ser. B Biol. Sci. 271, 397-405.

85. Fortin, D., Beyer, H.L., Boyce, M.S., Smith, D.W., Duchesne, T., and Mao, J.S. (2005). Wolves influence elk movements: behavior shapes a trophic cascade in Yellowstone National Park. Ecology 86, 1320-1330.

86. Bump, J.K., Peterson, R.O., and Vucetich, J.A. (2009). Wolves modulate soil nutrient heterogeneity and foliar nitrogen by configuring the distribution of ungulate carcasses. Ecology 90, 3159-3167.

87. Ripple, W.J., and Beschta, R.L. (2012). Trophic cascades in Yellowstone: the first 15 years after wolf reintroduction. Biol. Conserv. 145, 205-213.

88. Schrama, M., de Haan, J.J., Kroonen, M., Verstegen, H., and Van der Putten, W.H. (2018). Crop yield gap and stability in organic and conventional farming systems. Agric. Ecosyst. Environ. 256, 123-130.

89. Banerjee, S., Walder, F., Büchi, L., Meyer, M., Held, A.Y., Gattinger, A., Keller, T., Charles, R., and van der Heijden, M.G.A. (2019). Agricultura intensification reduces microbial network complexity and the abundance of keystone taxa in roots. ISME J. 13, 1722-1736.

90. Veen, C., Wubs, J., Bardgett, R., Barrios, E., Bradford, M., Carvalho, S., De Deyn, G., de Vries, F., Giller, K.E., Kleijn, D., et al. (2019). Applying the aboveground-belowground interaction concept in agriculture: spatiotemporal scales matter. Front. Ecol. Evol. 7, 300.

91. Griffiths, J.R., Kadin, M., Nascimento, F.J.A., Tamelander, T., Törnroos, A., Bonaglia, S., Bonsdorff, E., Brüchert, V., Gårdmark, A., Järnström, M., et al. (2017). The importance of benthic-pelagic coupling for marine ecosystem functioning in a changing world. Glob. Chang. Biol. 23, 2179-2196.

92. Berdugo, M., Kéfi, S., Soliveres, S., and Maestre, F.T. (2017). Plant spatial patterns identify alternative ecosystem multifunctionality states in global drylands. Nat. Ecol. Evol. 1, 3.

93. Glassman, S.I., Wang, I.J., and Bruns, T.D. (2017). Environmental filtering by $\mathrm{pH}$ and soil nutrients drives community assembly in fungi at fine spatial scales. Mol. Ecol. 26, 6960-6973.

94. Burkle, L.A., Marlin, J.C., and Knight, T.M. (2013). Plant-pollinator interactions over 120 years: loss of species, co-occurrence, and function. Science 339, 1611-1615. 
95. Bardgett, R.D., Manning, P., Morriën, E., and De Vries, F.T. (2013). Hierarchical responses of plant-soil interactions to climate change: consequences for the global carbon cycle. J. Ecol. 101, 334-343.

96. Warren, R.J., and Bradford, M.A. (2014). Mutualism fails when climate response differs between interacting species. Glob. Chang. Biol. 20, 466-474.

97. Collins, S.L., Avolio, M.L., Gries, C., Hallett, L.M., Koerner, S.E., La Pierre, K.J., Rypel, A.L., Sokol, E.R., Fey, S.B., Flynn, D.F.B., et al. (2018). Temporal heterogeneity increases with spatial heterogeneity in ecological communities. Ecology 99, 858-865.

98. Carpenter, S.R., Cole, J.J., Pace, M.L., Batt, R., Brock, W.A., Cline, T., Coloso, J., Hodgson, J.R., Kitchell, J.F., Seekell, D.A., et al. (2011). Early warnings of regime shifts: a whole-ecosystem experiment. Science (80-.) 332, 1079-1082.

99. Ochoa-Hueso, R., Risch, A.C., Collins, S.L., Eisenhauer, N., van der Putten, W.H., and van der Putten, W.H. (2020). Ecosystem and biogeochemical coupling in terrestrial ecosystems under global change: a roadmap for synthesis and call for data. Soil Org. 92, 1-7.

100. Barmentlo, S.H., Schrama, M., van Bodegom, P.M., de Snoo, G.R., Musters, C.J.M., and Vijver, M.G. (2019). Neonicotinoids and fertilizers jointly structure naturally assembled freshwater macroinvertebrate communities. Sci. Total Environ. 691, 36-44.

101. Musters, C.J.M., leromina, O., Barmentlo, S.H., Hunting, E.R., Schrama, M., Cieraad, E., Vijver, M.G., and van Bodegom, P.M. (2019). Partitioning the impact of environmental drivers and species interactions in dynamic aquatic communities. Ecosphere 10, e02910.

102. Postler, T.S., and Ghosh, S. (2017). Understanding the holobiont: how microbial metabolites affect human health and shape the immune system. Cell Metab 26, 110-130.

103. Vandenkoornhuyse, P., Quaiser, A., Duhamel, M., Le Van, A., and Dufresne, A. (2015). The importance of the microbiome of the plant holobiont. New Phytol. 206, 1196-1206.

104. Bourne, D.G., Garren, M., Work, T.M., Rosenberg, E., Smith, G.W., and Harvell, C.D. (2009). Microbial disease and the coral holobiont. Trends Microbiol. 17, 554-562.

105. Tilg, H., and Adolph, T.E. (2015). Influence of the human intestinal microbiome on obesity and metabolic dysfunction. Curr. Opin. Pediatr. 26, 496-501.

106. Xu, X., Wang, Z., and Zhang, X. (2015). The human microbiota associated with overall health. Crit. Rev. Biotechnol. 35, 129-140.

107. Kurakin, A., and Bredesen, D.E. (2020). Alzheimer's disease as a systems network disorder: chronic stress/dyshomeostasis, innate immunity, and genetics. Aging (Albany. NY) 12, 17815-17844.

108. Pievani, M., de Haan, W., Wu, T., Seeley, W.W., and Frisoni, G.B. (2011). Functional network disruption in the degenerative dementias. Lancet Neurol. 10, 829-843.

109. Bonda, D.J., Lee, H., Blair, J.A., Zhu, X., Perry, G., and Smith, M.A (2011). Role of metal dyshomeostasis in Alzheimer's disease. Metallomics 3, 267-270.

110. Calderón-Garcidueñas, L., Torres-Jardón, R., Kulesza, R.J., Mansour, Y., González-González, L.O., Gónzalez-Maciel, A., Reynoso-Robles, R., and Mukherjee, P.S. (2020). Alzheimer disease starts in childhood in polluted metropolitan Mexico City. A major health crisis in progress. Environ. Res. 183, 109137.

111. Ochoa-Hueso, R. (2017). Global change and the soil microbiome: a human-health perspective. Front. Ecol. Evol. 5, 71.

112. Charalambous, T., Tur, C., Prados, F., Kanber, B., Chard, D.T., Ourselin, S., Clayden, J.D., Gandini Wheeler-Kingshott, C., Thompson, A.J., and Toosy, A.T. (2019). Structural network disruption markers explain disability in multiple sclerosis. J. Neurol. Neurosurg. Psychiatry 90, 219-226.

113. Radisky, D., Muschler, J., and Bissell, M.J. (2002). Order and disorder: the role of extracellular matrix in epithelial cancer. Cancer Invest. 20, 139-153.

114. Fridley, J.D., Grime, J.P., Askew, A.P., Moser, B., and Stevens, C.J. (2011). Soil heterogeneity buffers community response to climate change in species-rich grassland. Glob. Chang. Biol. 17, 2002-2011.

115. Grime, J.P., Fridley, J.D., Askew, A.P., Thompson, K., Hodgson, J.G. and Bennett, C.R. (2008). Long-term resistance to simulated climate change in an infertile grassland. Proc. Natl. Acad. Sci. U. S. A. 105 10028-10032.

116. Ochoa-Hueso, R., Piñeiro, J., Hasegawa, S., Illanas, S., Miranda, $H$., Reverter, M., and Power, S.A. (2021). Spatial homogenization of understory plant communities under $\mathrm{eCO}_{2}$ in a mature Eucalyptus woodland. J. Ecol. 109, 1386-1395.
117. Fowler, D., Coyle, M., Skiba, U., Sutton, M.A., Cape, J.N., Reis, S., Sheppard, L.J., Jenkins, A., Grizzetti, B., Galloway, J.N., et al. (2013). The global nitrogen cycle in the twenty-first century. Philos. Trans. R. Soc. Lond. B. Biol. Sci. 368, 20130164.

118. Bobbink, R., Hicks, K., Galloway, J., Spranger, T., Alkemade, R., Ashmore, M., Bustamante, M., Cinderby, S., Davidson, E., Dentener, F. et al. (2010). Global assessment of nitrogen deposition effects on terres trial plant diversity: a synthesis. Ecol. Appl. 20, 30-59.

119. Alberti, M. (2015). Eco-evolutionary dynamics in an urbanizing planet. Trends Ecol. Evol. 30, 114-126.

120. Berdugo, M., Delgado-Baquerizo, M., Soliveres, S., Hernández-Clemente, R., Zhao, Y., Gaitán, J.J., Gross, N., Saiz, H., Maire, V., Lehmann, A., et al. (2020). Global ecosystem thresholds driven by aridity. Sci. (80- 367, 787-790.

121. Collins, S.L., Belnap, J., Grimm, N.B., Rudgers, J.A., Dahm, C.N., D’Odorico, P., Litvak, M., Natvig, D.O., Peters, D.C., Pockman, W.T., et al. (2014). A multiscale, hierarchical model of pulse dynamics in aridland ecosystems. Annu. Rev. Ecol. Evol. Syst. 45, 397-419.

122. Wei, C., Yu, Q., Bai, E., Lü, X., Li, Q., Xia, J., Kardol, P., Liang, W., Wang, Z., and Han, X. (2013). Nitrogen deposition weakens plant-microbe interactions in grassland ecosystems. Glob. Chang. Biol. 19, 3688-3697.

123. Montoya, J.M., Pimm, S.L., and Solé, R.V. (2006). Ecological networks and their fragility. Nature 442, 259-264.

124. Massol, F., Gravel, D., Mouquet, N., Cadotte, M.W., Fukami, T., and Leibold, M.A. (2011). Linking community and ecosystem dynamics through spatial ecology. Ecol. Lett. 14, 313-323.

125. Higgins, P.A.T., Mastrandrea, M.D., and Schneider, S.H. (2002). Dynamics of climate and ecosystem coupling: abrupt changes and multiple equilibria. Philos. Trans. R. Soc. B Biol. Sci. 357, 647-655.

126. Resch, M.C., Schütz, M., Graf, U., Wagenaar, R., van der Putten, W.H., and Risch, A.C. (2019). Does topsoil removal in grassland restoration benefit both soil nematode and plant communities? J. Appl. Ecol. 56, 1782-1793.

127. Resch, M.C., Schütz, M., Buchmann, N., Frey, B., Graf, U., van der Putten, W.H. Zimmermann, S., and Risch, A.C. (2021). Evaluating long-term success in grassland restoration: an ecosystem multifunctionality approach. Ecol. Appl. 31, e02271.

128. Creamer, R.E., Hannula, S.E., Leeuwen, J.P.V., Stone, D., Rutgers, M. Schmelz, R.M., Ruiter, P.C.d., Hendriksen, N.B., Bolger, T., Bouffaud, M.L., et al. (2016). Ecological network analysis reveals the inter-connection between soil biodiversity and ecosystem function as affected by land use across Europe. Appl. Soil Ecol. 97, 112-124.

129. Solé, R.V., Montañez, R., Rodriguez-Amor, D., Vidiella, B., and Sardanyés, J. (2018). Population dynamics of synthetic terraformation motifs. R. Soc. Open Sci. 5, 180121.

130. Collins, S.L., Sinsabaugh, R.L., Crenshaw, C., Green, L., Porras-Alfaro, A., Stursova, M., and Zeglin, L.H. (2008). Pulse dynamics and microbia processes in aridland ecosystems. J. Ecol. 96, 413-420.

131. Maestre, F.T., Solé, R., and Singh, B.K. (2017). Microbial biotechnology as a tool to restore degraded drylands. Microb. Biotechnol. 10, 1250-1253.

132. Ochoa-Hueso, R., Eldridge, D.J, Delgado-Baquerizo, M., Soliveres, S., Bowker, M.A., Gross, N., Le Bagousse-Pinguet, Y., Quero, J.L., García-Gómez, M., Valencia, E., et al. (2018). Soil fungal abundance and plant functional traits drive fertile island formation in global drylands. J. Ecol. 106, 242-253.

133. Lundberg, J., and Moberg, F. (2003). Mobile link organisms and ecosystem functioning: implications for ecosystem resilience and management. Ecosystems 6, 87-98.

134. Jones, C.G., Lawton, J.H., and Shachak, M. (1996). Organisms as ecosystem engineers. In Ecosystem Management: Selected Readings, F.B. Samson and F.L. Knopf, eds. (Springer New York), pp. 130-147.

135. Ellison, A.M., Bank, M.S., Clinton, B.D., Colburn, E.A., Elliott, K., Ford, C.R., Foster, D.R., Kloeppel, B.D., Knoepp, J.D., Lovett, G.M., et al (2005). Loss of foundation species: consequences for the structure and dynamics of forested ecosystems. Front. Ecol. Environ. 3, 479-486.

136. Finlay, R.D. (2008). Ecological aspects of mycorrhizal symbiosis: with special emphasis on the functional diversity of interactions involving the extraradical mycelium. J. Exp. Bot. 59, 1115-1126.

137. Phillips, R.P., Brzostek, E., and Midgley, M.G. (2013). The mycorrhizal associated nutrient economy: a new framework for predicting carbonnutrient couplings in temperate forests. New Phytol. 199, 41-51.

138. Barto, E.K., Weidenhamer, J.D., Cipollini, D., and Rillig, M.C. (2012) Fungal superhighways: do common mycorrhizal networks enhance below ground communication? Trends Plant Sci. 17, 633-637. 
139. Johnson, D., and Gilbert, L. (2015). Interplant signalling through hyphal networks. New Phytol. 205, 1448-1453.

140. Caruso, T., Hogg, I.D., Nielsen, U.N., Bottos, E.M., Lee, C.K., Hopkins, D.W., Cary, S.C., Barrett, J.E., Green, T.G.A., Storey, B.C., et al. (2019). Nematodes in a polar desert reveal the relative role of biotic interactions in the coexistence of soil animals. Commun. Biol. 2, 63.

141. Xiong, W., Jousset, A., Guo, S., Karlsson, I., Zhao, Q., Wu, H., Kowalchuk, G.A., Shen, Q., Li, R., and Geisen, S. (2018). Soil protist communities form a dynamic hub in the soil microbiome. ISME J. 12, 634-638.
142. Risch, A.C., Zimmermann, S., Ochoa-Hueso, R., Schütz, M., Frey, B. Firn, J.L., Fay, P.A., Hagedorn, F., Borer, E.T., Seabloom, E.W., et al. (2019). Soil net nitrogen mineralisation across global grasslands. Nat. Commun. 10, 4981.

143. Heijnen, C.E., Hok-A-Hin, C.H., and Van Veen, J.A. (1992). Improvements to the use of bentonite clay as a protective agent, increasing survival levels of bacteria introduced into soil. Soil Biol. Biochem. 24, 533-538.

144. Cuadros, J. (2017). Clay minerals interaction with microorganisms: a review. Clay Miner. 52, 235-261. 